\title{
Bioenergetics and Biological Electron Transport
}

\author{
Philip N. Bartlett \\ School of Chemistry, University of Southampton, Southampton, SO17 1BJ, UK
}

\subsection{INTRODUCTION}

Electron transfer reactions play a central role in all biological systems because they are essential to the processes by which biological cells capture and use energy. These electron transfer reactions occur in highly organised ways, in electron transport chains in which electron transfer occurs in an ordered way between specific components, and these electron transfer reactions occur at interfaces. In this chapter we will explore the principles behind the organisation and operation of these electron transfer chains from an electrochemical perspective. We will examine the guiding physical principles which govern the efficient operation of biological electron transfer. As we will see, several guiding principles emerge: the tuning of redox potentials for different components in the electron transfer chain to optimise energy efficiency, the control of distance between redox centres to control the kinetics of electron transfer and to achieve specificity, the role of an insulating lipid bilayer to separate charge and store electrochemical energy. Such a study is informative, not only because it tells us about the structure, organisation and function of biological systems, but also because we can learn useful lessons from the study of biological electron transfer systems which have evolved over millions of years which we can use to guide our design of electrochemical systems. For example, electrocatalysis of the four-electron reduction of oxygen to water at neutral $\mathrm{pH}$ remains a key barrier to the development of efficient polymer electrolyte membrane (PEM) fuel cells. This same reaction is an important component in the mitochondrial electron transport chain where it is achieved using non-noble metal catalytic sites. A detailed understanding of this biological reaction may give clues to the design of new electrocatalysts for fuel cells. Similarly an understanding of the organisation, light harvesting and electron transfer reactions in the photosynthetic systems in plants and bacteria can inform our design of artificial photosynthetic systems for solar energy conversion. Closer to home, an understanding of the principles which govern efficient biological electron transfer is essential if we wish to exploit biological electron transfer components, such as oxidoreductase enzymes, NADH-dependent dehydrogenases or redox proteins, in biosensors, biofuel cells or bioelectrosynthesis.

This chapter is conceived as a general introduction to biological electron transfer processes for those with little or no prior knowledge of the subject, but with a background in chemistry or electrochemistry. As such it should serve as an introduction to the more specific material to be found in the chapters which follow. At the same time I have tried to emphasise the underlying principles, as seen from an electrochemical perspective, and to bring out similarities rather than to emphasise the differences in detail between the different electron transport chains. Such an interest in the organisation and principles which guide biological electron transfer is directly relevant to current interest in integrated chemical systems [1].

Broadly this chapter is organised as follows. We begin with a very simple description of the different types of

Bioelectrochemistry: Fundamentals, Experimental Techniques and Applications Edited by Philip Bartlett (C) 2008 John Wiley \& Sons, Ltd 
biological cell, bacterial, plant and animal, their internal organisation and the different structures within them. We then consider the structure of biological cells from an electrochemical perspective focusing on the processes of energy transduction and utilisation. This is followed by a more detailed description of the electron transfer chains in the mitochondria and in the photosynthetic membrane and the different redox centres that make up the electron transport chains in these systems. We then describe the governing principles which emerge as the important features in all of these electron transfer processes, before concluding with a discussion of the way these processes are used to drive the thermodynamically uphill synthesis of adenosine triphosphate (ATP).

\subsection{BIOLOGICAL CELLS}

All living matter is made up of cells and these cells share many common features in terms of their structure and the chemical components which make up the cell. The different types of living cell, from the simplest bacteria to complex plant and mammalian cells, carry out many of their fundamental processes in the same way. Thus the production of chemical energy by conversion of glucose to carbon dioxide is carried out in a similar way across all biological cells. This similarity reflects the common ancestry of all living cells and the process of evolution.

In this section we focus on the internal structure of the different types of biological cell. For a more detailed discussion of biological cells the reader is directed to modern biochemistry or cell biology texts such as that by Lodish and colleagues which provides a beautifully illustrated account of the subject [2]. Biological cells can be divided into two classes: eukaryotic and prokaryotic (Figure 1.1). The eukaryotes include all plants and animals as well as many single cell organisms. The prokaryotes have a simpler cell structure and include all bacteria; they are further divided into the eubacteria and archaebacteria. In the prokaryotic cell there is a single plasma membrane, a phospholipid bilayer, which separates the inside of the cell from the outer world, although in some cases there can also be simple internal photosynthetic membranes.

In contrast, in eukaryotes the inner space within the cell is further divided into a number of additional structures called organelles. These are specialised structures surrounded by their own plasma membranes. Thus, within the eukaryotic cell we find specialised structures, such as the nucleus, which contains the cell's DNA and which directs the synthesis on RNA within the cell, peroxisomes, which metabolise hydrogen peroxide, mitochondria, where ATP is generated by oxidation of small molecules, and, in plants, chloroplasts, where light is captured. It is the last two of these, the mitochondria and the chloroplasts which are of most interest to us here since both are central to biological energy transduction and both function electrochemically. These same functions of energy transduction occur in prokaryotes,

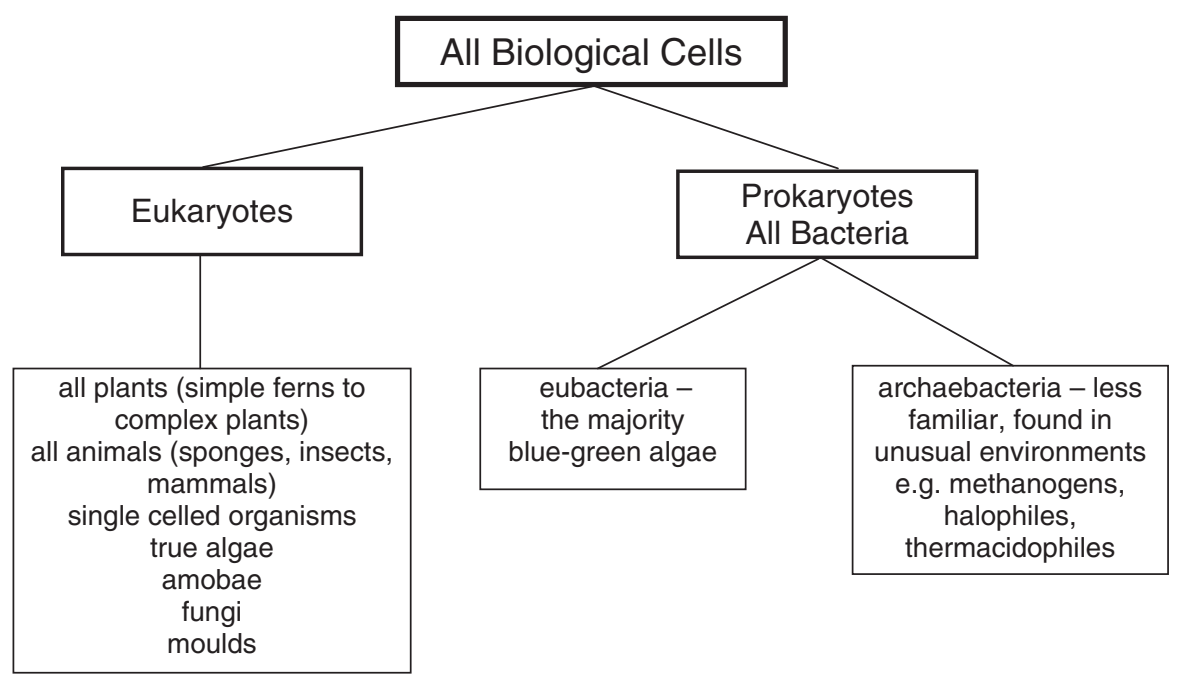

Figure 1.1 The general classification of biological cells. 
but in this case they are associated with the outer cell membrane.

Below we give a more detailed account of the electron transfer processes which occur in the mitochondrion and chloroplast, but for now we concentrate on the essential common features. Both processes, the oxidation of small molecules to generate energy in the mitochondrion and the capture of light and its transduction into energy that the cell can use in the chloroplast, occur across energy transducing membranes. In both cases the final product is ATP (see below), a high energy species that is used elsewhere in the cell to drive catabolism (the synthesis of molecules within the cell) and other living processes. An essential feature of the phospholipid bilayers which make up the plasma membranes of the cell and the different organelles within the eukaryotic cell is that although they are permeable to gases such as oxygen and carbon dioxide, they are impermeable to larger molecules such as amino acids or sugars and they are impermeable to ions such as $\mathrm{H}^{+}, \mathrm{K}^{+}$or $\mathrm{Cl}^{-}$. This allows the cell to control the composition of the solution on the two sides of the membrane separately, a process which is achieved by the presence of specific transmembrane proteins, or permeases, within the cell membrane, which control transport of molecules and ions across the membrane.

The energy transducing membranes of eukaryotes and prokaryotes, that is the plasma membrane of simple prokaryotic cells such as bacteria and blue-green algae, the inner membrane of mitochondria and the thylakoid membrane of chloroplasts in eukaryotes, share many common features. All of these membranes have two distinct protein assemblies: the ATPase at which ADP is converted to adenosine triphosphate (ATP) and the energy source electron transport chain which provides the thermodynamic driving force to the synthesis of ATP. These two processes are linked by the directed flow of electrons and protons across the membrane in order to establish an electrochemical potential which is used to drive ATP synthesis. This chemiosmotic model of biological energy transduction, which is essentially an electrochemical model, was first described by Mitchell in 1961 and was recognised by the award of the Nobel prize for chemistry in $1978[3,4]$.

\subsection{CHEMIOSMOSIS}

The key concept in the chemiosmotic theory is that the synthesis of ATP is linked to the energy source electron transfer chain through the transmembrane proton motive force that is set up. This proton motive force is made up of a contribution from the proton concentration gradient across the membrane, as well as the potential difference across the membrane. Figure 1.2 shows a simplified picture for the mitochondrial membrane and the thylakoid membrane of the chloroplast. In the mitochondria and aerobic bacteria, energy from the oxidation of carbon compounds, such as glucose, is used to pump protons across the membrane. In photosynthesis, energy absorbed from light is used to pump protons across the membrane. In both cases the protons are pumped from the inside, cytoplasmic face, to the outside, exoplasmic face, of the membrane. In addition to the production of ATP, this proton motive force can also be used by the cell to drive other processes such as the rotation of flagella to allow bacteria to swim around in solution or to drive the transport of species across the cell membrane against the existing concentration gradient. Clearly, an essential feature of this energy coupling between the transduction and its use in ATP synthesis or other processes is the presence of an insulating, closed membrane which is impermeable to the transport of protons, since without this it would not be possible to build up a transmembrane proton motive force.

\subsubsection{The Proton Motive Force}

In this section we consider the thermodynamics of the proton motive force. The proton motive force is a combination of the potential difference across the membrane and the difference in proton concentration across the membrane. Both contribute to the available free energy.

Consider an impermeable membrane separating two solutions, $\alpha$ and $\beta$, as shown in Figure 1.3. The electrochemical potential of the proton in solution $\alpha, \bar{\mu}_{\mathrm{H}^{+}}(\alpha)$, is given by

$$
\bar{\mu}_{\mathrm{H}^{+}}(\alpha)=\mu_{\mathrm{H}^{+}}^{0}(\alpha)+R T \ln a_{\mathrm{H}^{+}}(\alpha)+F \phi(\alpha)
$$

where $\mu_{\mathrm{H}^{+}}^{0}(\alpha)$ is the chemical potential of the proton in solution $\alpha$ under standard conditions, $R$ is the gas constant, $T$ the temperature in Kelvin, $a_{\mathrm{H}^{+}}(\alpha)$ is the activity of protons in solution $\alpha, F$ the Faraday constant and $\phi(\alpha)$ the potential. Notice that there are three contributions to the electrochemical potential of the proton in solution: a chemical term given by $\mu_{\mathrm{H}^{+}}^{0}(\alpha)$, an activity (or concentration) dependent term, and a term which depends on the potential. Similarly, for the protons in solution $\beta$, we can write

$$
\bar{\mu}_{\mathrm{H}^{+}}(\beta)=\mu_{\mathrm{H}^{+}}^{0}(\beta)+R T \ln a_{\mathrm{H}^{+}}(\beta)+F \phi(\beta)
$$



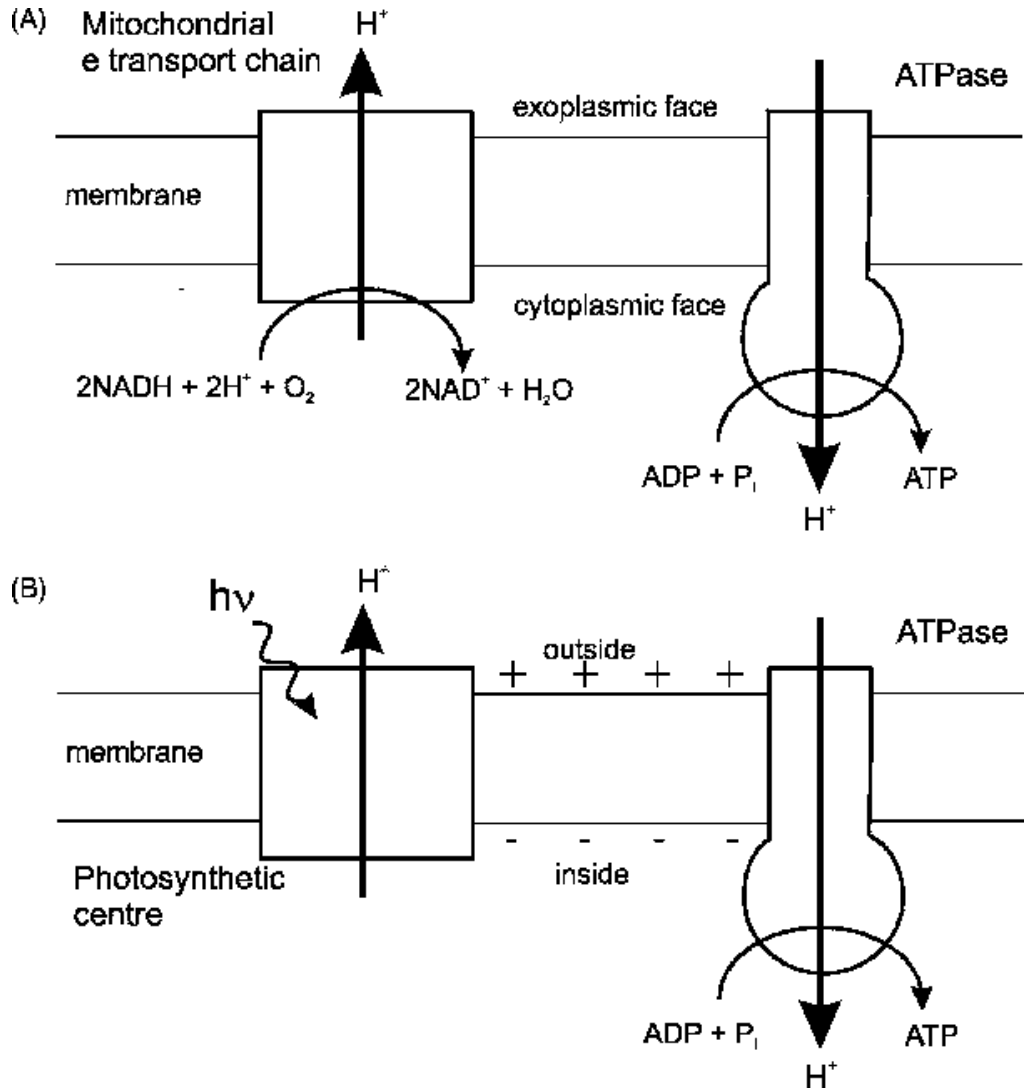

Figure 1.2 A general overview of: (A) mitochondrial respiration and (B) photosynthesis.

At equilibrium, by definition the electrochemical potentials in the two solutions will be equal. That is

$$
\bar{\mu}_{\mathrm{H}^{+}}(\alpha)=\bar{\mu}_{\mathrm{H}^{+}}(\beta)
$$

However, a living cell is not at equilibrium. The difference in the electrochemical potential of the proton across the membrane, $\Delta \bar{\mu}_{\mathrm{H}^{+}}$, is a measure of the distance of the system from equilibrium and is given by

$$
\Delta \bar{\mu}_{\mathrm{H}^{+}}=\bar{\mu}_{\mathrm{H}^{+}}(\alpha)-\bar{\mu}_{\mathrm{H}^{+}}(\beta)
$$

so that

$$
\begin{aligned}
\Delta \bar{\mu}_{\mathrm{H}^{+}}= & \mu_{\mathrm{H}^{+}}^{0}(\alpha)+R T \ln a_{\mathrm{H}^{+}}(\alpha)+F \phi(\alpha) \\
& -\mu_{\mathrm{H}^{+}}^{0}(\beta)-R T \ln a_{\mathrm{H}^{+}}(\beta)-F \phi(\beta)
\end{aligned}
$$

We can simplify Equation (1.5) since the standard chemical potential of the proton is the same in both solutions, thus

$$
\mu_{\mathrm{H}^{+}}^{0}(\alpha)=\mu_{\mathrm{H}^{+}}^{0}(\beta)
$$

After collecting together terms Equation (1.5) becomes

$$
\Delta \bar{\mu}_{\mathrm{H}^{+}}=R T \ln \left\{\frac{a_{\mathrm{H}^{+}}(\alpha)}{a_{\mathrm{H}^{+}}(\beta)}\right\}+F \Delta \phi
$$

or

$$
\Delta \bar{\mu}_{\mathrm{H}^{+}}=-2.303 R T \Delta \mathrm{pH}+F \Delta \phi
$$

The proton motive force itself is then

$$
\mathrm{pmf}=\frac{\Delta \bar{\mu}_{\mathrm{H}^{+}}}{F}=\frac{-2.303 R T \Delta \mathrm{pH}}{F}+\Delta \phi
$$




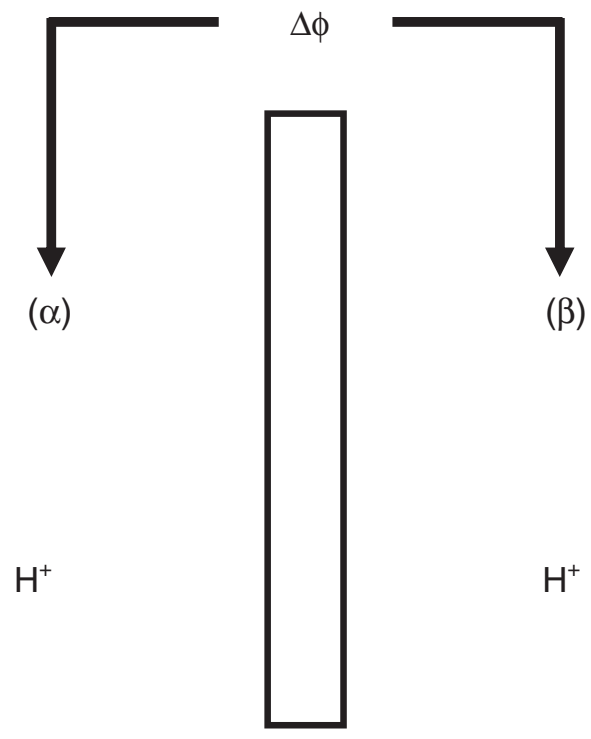

Figure 1.3 Scheme for a transmembrane potential.

At room temperature

$$
\mathrm{pmf} / \mathrm{mV}=-59 \times \Delta \mathrm{pH}+\Delta \phi
$$

Thus the proton motive force is made up of two components: the contribution from the difference in proton concentration across the membrane, and the contribution from the potential difference across the membrane. Thus if the membrane is permeable to $\mathrm{Cl}^{-}$or if $\mathrm{H}^{+}$exchanges with another cation (such as $\mathrm{K}^{+}$) the contribution from the potential difference $\Delta \phi$ will be small but $\Delta \mathrm{pH}$ can still be large. This is the situation for the thylakoid membrane in photosynthesis. In contrast, if the membrane is impermeable to anions, $\Delta \phi$ can make a more significant contribution. This is the case in the respiring mitochondrion where the total proton motive force of around $220 \mathrm{mV}$ is made up of a transmembrane potential of $160 \mathrm{mV}$ (with the inside of the mitochondrion at a negative potential with respect to the outside - the protons are pumped from inside to out) together with a $60 \mathrm{mV}$ contribution from the one unit $\mathrm{pH}$ difference across the membrane.

\subsubsection{The Synthesis of ATP}

The second part of the story is the synthesis of ATP from ADP and inorganic phosphate and we now turn our attention to the thermodynamics of this process. Adenosine triphosphate, ATP (Figure 1.4), is found in all types of living organism and is the universal mode of transfer-<smiles>Nc1ncnc2c1ncn2C(O)[C@H](O)[C@H](O)OCOP(=O)([O-])OP(=O)([O-])[O-]</smiles>

Adenosine Diphosphate (ADP)<smiles>Nc1ncnc2c1ncn2C(O)C(O)COP(=O)([O-])OP(=O)([O-])OP(=O)([O-])[O-]</smiles>

Adenosine Triphosphate (ATP)

Figure 1.4 The structures of adenosine diphosphate (ADP) and adenosine triphosphate (ATP).

ring energy around the cell in order to drive all the endergonic $\left(\Delta G_{\mathrm{rxn}}>0\right)$ reactions necessary for life. These include the synthesis of cellular macromolecules, such as DNA, RNA, proteins and polysaccharides, the synthesis of cellular constituents, such as phospholipids and metabolites, and cellular motion including muscle contraction. In humans it is estimated that on average $40 \mathrm{~kg}$ of ATP are used every day corresponding to 1000 turnovers between ADP, ATP and back to ADP for every molecule of ADP in the body each day [5]. In ATP the energy is stored in highenergy phosphoanhydride bonds and hydrolysis of these bonds to produce ADP or AMP (adenosine monophosphate) releases this energy

$$
\mathrm{ATP}^{4-}+\mathrm{H}_{2} \mathrm{O} \rightarrow \mathrm{ADP}^{3-}+\mathrm{H}^{+}+\mathrm{HPO}_{4}{ }^{2-}
$$

or

$$
\mathrm{ATP}^{4-}+\mathrm{H}_{2} \mathrm{O} \rightarrow \mathrm{AMP}^{2-}+\mathrm{H}^{+}+\mathrm{HP}_{2} \mathrm{O}_{7}^{3-}
$$

where $\mathrm{HPO}_{4}{ }^{2-}$ is inorganic phosphate and $\mathrm{HP}_{2} \mathrm{O}_{7}{ }^{3-}$ is inorganic pyrophosphate. In the case of Reaction (1.12), the inorganic pyrophosphate produced is hydrolysed to inorganic phosphate by the enzyme pyrophosphatase. Both reactions, (1.11) and (1.12), have a free energy change of $-30.5 \mathrm{~kJ} \mathrm{~mol}^{-1}$ in the standard state at $\mathrm{pH} 7$. When we take account of the actual concentrations of the different species ( $2.5 \mathrm{mM}$ for ATP, $0.25 \mathrm{mM}$ for ADP and 
$2.0 \mathrm{mM}$ for $\mathrm{HPO}_{4}{ }^{2-}$ ) this gives a value of about $-52 \mathrm{~kJ}$ $\mathrm{mol}^{-1}$ in the living cell [6]. If we assume a transmembrane proton motive force of, say, $200 \mathrm{mV}$ this corresponds to a free energy change for each proton translocated across the membrane of $-19.3 \mathrm{~kJ} \mathrm{~mol}^{-1}$. Thus it is necessary to transfer at least two protons across the membrane for each ATP molecule synthesised.

\subsection{ELECTRON TRANSPORT CHAINS}

We now turn our attention in more detail onto the electron transport chains in mitochondria, in the chloroplast and in bacteria and focus on the processes occurring in these electron transport chains. As we have seen, electron transport in these systems is central to the process of energy generation in living systems. We can therefore expect these systems to have evolved to operate efficiently and it is of interest to study the way that they operate and the underlying principles involved. We begin by considering the mitochondrial electron transport chain.

\subsubsection{The Mitochondrion}

The main source of energy in non-photosynthetic cells is glucose. The standard free energy for the complete oxidation of glucose to carbon dioxide and water is $-2870 \mathrm{~kJ} \mathrm{~mol}^{-1}$ and in the cell this is coupled to the synthesis of up to 32 moles of ATP for every mole of glucose oxidised. In eukaryotic cells, the first stages of this process occur in the cytosol, the solution contained by the outer cell membrane, where two moles of ATP are generated by the conversion of glucose to two molecules of pyruvate in a process called glycolysis (Figure 1.5). In addition to two molecules of ATP, the process generates two molecules of NADH. The pyruvate generated in the cytosol is transported to the mitochondria where up to 30 further ATP molecules are generated by the complete oxidation of the pyruvate to carbon dioxide. In addition, the two molecules of NADH formed in glycolysis reduce two molecules of $\mathrm{NAD}^{+}$within the mitochondrion, which are then oxidised back to $\mathrm{NAD}^{+}$by oxygen as part of the mitochondrial electron transport chain. Thus the mitochondrion is the central power plant, or more precisely the central fuel cell, which powers the eukaryotic cell, and these cells generally contain hundreds of mitochondria [7]. In humans, for example, it has been calculated that at rest the typical transmembrane current, summed over all the mitochondria, amounts to just over $500 \mathrm{~A}$ (assuming a power consumption of $116 \mathrm{~W}$ and a transmembrane potential of $0.2 \mathrm{~V}$ ) [8]. Given the central role of mitochondria in energy production, it is not surprising that mitochondrial

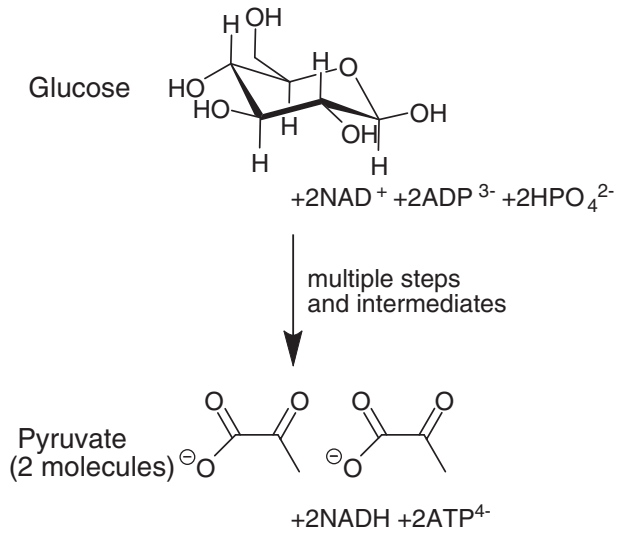

Figure 1.5 The overall reaction for glycolysis.

defects are implicated with a wide range of degenerative diseases [7]. It is also worth noting that mitochondria are also essential in the photosynthetic cells of plants for the production of ATP during dark periods and for the generation of ATP in all non-photosynthetic plant cells (such as root cells).

The mitochondrion is around 1 or 2 microns in length and 0.1 to 0.5 microns in diameter and is therefore one of the larger organelles in the eukaryotic cell. The mitochondrion, Figure 1.6, contains two separate membranes [9]. The outer membrane is made up of about $50 \%$ lipid and $50 \%$ of proteins called porins, which allow molecules with molecular weight up to $10000 \mathrm{Da}$ to pass through. The inner membrane is much less porous and is about $20 \%$ lipid and $80 \%$ protein. The inner membrane has a large number of invaginations, called cristae, which increase the surface area of the membrane and it is across this inner membrane that electron and proton transport occur in the mitochondrial electron transport chain. The

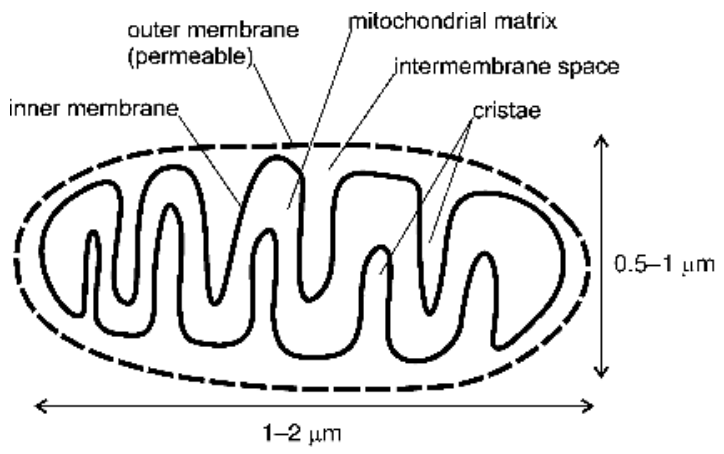

Figure 1.6 The structure of the mitochondrion. 


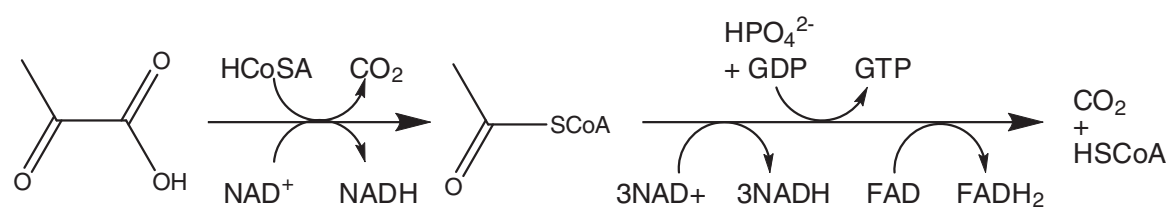

Figure 1.7 The citric acid cycle. HCoSA is free coenzyme A; GDP and GTP are guanosine diphosphate and guanosine triphosphate, respectively.

solution inside the mitochondrion has a high protein content, around $50 \%$ by weight, and therefore is quite viscous.

Broadly, three processes occur within the mitochondria. First, the oxidation of pyruvate to carbon dioxide with the generation of NADH and $\mathrm{FADH}_{2}$ through the citric acid cycle (Figure 1.7). Second, the oxidation of NADH and $\mathrm{FADH}_{2}$, by molecular oxygen in the mitochondrial electron transport chain, to generate a proton motive force across the inner mitochondrial membrane. Third, the generation of ATP from ADP by $\mathrm{F}_{0} \mathrm{~F}_{1}$ ATPase, driven by the proton motive force across the inner membrane. This ATP is then exported from the mitochondrion to drive processes in other parts of the eukaryotic cell. In this chapter we will concentrate on the last two of these processes since they are essentially electrochemical, rather than chemical, in their nature. Here we examine the mitochondrial electron transport chain, a description of the $\mathrm{F}_{0} \mathrm{~F}_{1}$ ATPase is given in a later section.

Overall, the oxidation of one molecule of glucose produces 10 molecules of NADH and two molecules of $\mathrm{FADH}_{2}$. This process is reasonably efficient and incurs only about a $10 \%$ energy loss from that originally available in the glucose. In the electron transport chain, the reduced coenzymes are reoxidised in several distinct steps by molecular oxygen rather than in a single step - by using the electron transfer chain, the energy is released in a number of small, and therefore thermodynamically more efficient, steps. Overall, the oxidations of NADH and $\mathrm{FADH}_{2}$ are strongly exergonic $\left(\Delta G_{\mathrm{rxn}}<0\right)$ processes

$$
\begin{aligned}
\mathrm{NADH}+\mathrm{H}^{+}+{ }^{1} /{ }_{2} \mathrm{O}_{2} \rightarrow \mathrm{NAD}^{+}+\mathrm{H}_{2} \mathrm{O} \\
\Delta G=-220 \mathrm{~kJ} \mathrm{~mol}^{-1} \\
\mathrm{FADH}_{2}+{ }^{1 /} / \mathrm{O}_{2} \rightarrow \mathrm{FAD}+\mathrm{H}_{2} \mathrm{O} \\
\Delta G=-182 \mathrm{~kJ} \mathrm{~mol}^{-1}
\end{aligned}
$$

Since the conversion of ADP to ATP requires $30.5 \mathrm{~kJ}$ $\mathrm{mol}^{-1}$, the oxidation of one molecule of NADH or $\mathrm{FADH}_{2}$ is sufficiently exergonic to generate more that one molecule of ATP.
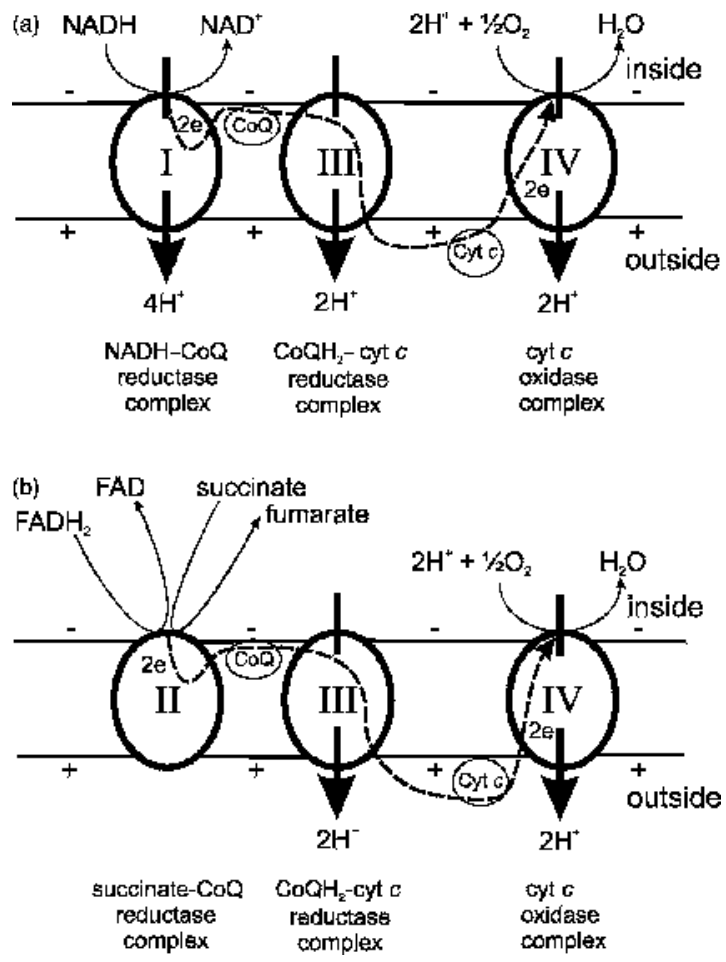

Figure 1.8 An overview of the mitochondrial electron transport chain: (a) Electron transfer from NADH to molecular oxygen; (b) electron transfer from $\mathrm{FADH}_{2}$ and succinate to molecular oxygen. I, II, III and IV are the four major transmembrane protein complexes of the mitochondrial electron transport chain. The processes leading to the pumping of protons across the membrane are indicated by the bold arrows. The broken arrow shows the pathway of sequential electron transfer down the chain. CoQ and Cyt $c$ are coenzyme $\mathrm{Q}$ and cytochrome $c$ respectively.

Figure 1.8 gives an overview of the mitochondrial electron transport chain $[2,10,11]$. It comprises several large proteins which span the inner mitochondrial membrane. As electrons are passed along the chain from $\mathrm{NADH}$ at one end, to oxygen at the other, protons are pumped across the membrane at several points as shown 
in the figure. Oxidation of NADH occurs at the NADHCoQ reductase complex (complex I in Figure 1.8a). This process is accompanied by the transfer of four protons across the membrane and the electrons from the NADH are passed to a molecule of coenzyme $\mathrm{Q}, \mathrm{CoQ}$, a hydrophobic quinone, which takes the electrons from the NADH-CoQ reductase complex and passes them to the $\mathrm{CoQH}_{2}-$ cyt $c$ reductase complex (complex III in Figure 1.8). Note that the structures of the individual redox centres in the different parts of electron transport chains are discussed in detail later in this chapter - for now we concentrate on the larger functional picture rather than the molecular detail. The reduced coenzyme $\mathrm{Q}$ passes the electrons to the $\mathrm{CoQH}_{2}-$ cyt $c$ reductase complex, where a further pair of protons are pumped across the membrane and the electrons are passed to two molecules of cytochrome $c$, cyt $c$, a soluble electron transfer protein. The cytochrome $c$ passes the electrons to the cyt $c$ oxidase complex (complex IV in Figure 1.8) where a further two protons are pumped across the membrane and the electrons end up on oxygen, producing water. The electrons from $\mathrm{FADH}_{2}$ are fed into the electron transfer chain in a similar way (Figure 1.8b). $\mathrm{FADH}_{2}$ is oxidised to FAD by the succinate-CoQ reductase complex (complex II in Figure 1.8b), with the generation of one molecule of reduced coenzyme Q. No protons are pumped across the membrane by this reaction. The reduced coenzyme $\mathrm{Q}$ produced from $\mathrm{FADH}_{2}$ joins that from NADH in passing its electrons to the $\mathrm{CoQH}_{2}$-cyt $c$ reductase complex and thence to the cyt $c$ oxidase complex and ultimately to molecular oxygen (Figure $1.8 \mathrm{~b}$ ). The succinate-CoQ reductase complex (complex II in Figure 1.8b) also catalyses the oxidation of succinate, produced by the citric acid cycle within the mitochondrion, to fumarate, with the generation of one molecule of reduced coenzyme Q which participates in the electron transport chain.

The four protein complexes, I to IV in Figure 1.8, are large multiunit proteins each containing several redox prosthetic groups (Table 1.1) and within the individual protein complexes, the redox prosthetic groups are carefully arranged in three dimensions so that the electrons are passed in an ordered fashion from one redox component to the next. Much progress has been made in the last few years in determining the structures of these large, membrane-bound proteins and the details of their operation. In the following sections we discuss electron transfer in each of the complexes in turn.

\subsubsection{The NADH-CoQ Reductase Complex}

The NADH-CoQ reductase complex, or complex I, is found in the mitochondria of eukaryotes and in the plasma membranes of purple photosynthetic bacteria and respiratory bacteria. The complex (Figure 1.9a) has an L-shape with two major sub-units, one predominantly within the membrane and the other protruding into the inner mitochondrial space containing the NADH reaction site [12-15]. The NADH-CoQ reductase complex is the most complex and largest of the proton pumping enzymes in the mitochondrion and is made up of about 30 separate sub-units; it is also, because of this complexity, the least well understood. The NADH reacts with a flavin mononucleotide (FMN) prosthetic group. From here the electrons are passed to several (eight or nine) iron-sulfur centres.

Table 1.1 The four protein complexes of the mitochondrial electron transport chain.

\begin{tabular}{|c|c|c|c|c|c|}
\hline & Complex & $\mathrm{RMM} / \mathrm{kDa}$ & Redox centres & Comments & Ref \\
\hline \multirow[t]{2}{*}{ I } & $\begin{array}{l}\mathrm{NADH}-\mathrm{CoQ} \\
\text { reductase }\end{array}$ & $>900$ & FMN & $\begin{array}{l}\text { transmembrane, pumps } \mathrm{H}^{+} \text {, } \\
\quad 43-46 \text { subunits }\end{array}$ & [12-15] \\
\hline & & & $\begin{array}{l}8 \text { or } 9 \mathrm{Fe}-\mathrm{S} \\
2 \text { quinones }\end{array}$ & & \\
\hline \multirow[t]{3}{*}{ II } & $\begin{array}{l}\text { Succinate-CoQ } \\
\text { reductase }\end{array}$ & 120 & FAD & $\begin{array}{l}\text { membrane bound, does not pump } \mathrm{H}^{+} \text {, } \\
4 \text { subunits }\end{array}$ & {$[11,22-24]$} \\
\hline & & & $3 \mathrm{Fe}-\mathrm{S}$ & & \\
\hline & & & 1 Heme $b$ & & \\
\hline \multirow[t]{2}{*}{ III } & $\begin{array}{l}\mathrm{CoQH}_{2}-\text { cyt } c \\
\quad \text { reductase }\end{array}$ & 240 & 2 Heme $b$ & $\begin{array}{l}\text { transmembrane, pumps } \mathrm{H}^{+}, 11 \text { subunits, } \\
\text { exits in membrane as functional dimmer }\end{array}$ & {$[28,31]$} \\
\hline & & & $\begin{array}{l}1 \text { Heme } c \\
1 \mathrm{Fe}-\mathrm{S}\end{array}$ & & \\
\hline IV & Cyt $c$ oxidase & 204 & $\begin{array}{l}2 \text { Heme } a \\
2 \mathrm{Cu}\end{array}$ & transmembrane, pumps $\mathrm{H}^{+}, 13$ subunits & [37-39] \\
\hline
\end{tabular}




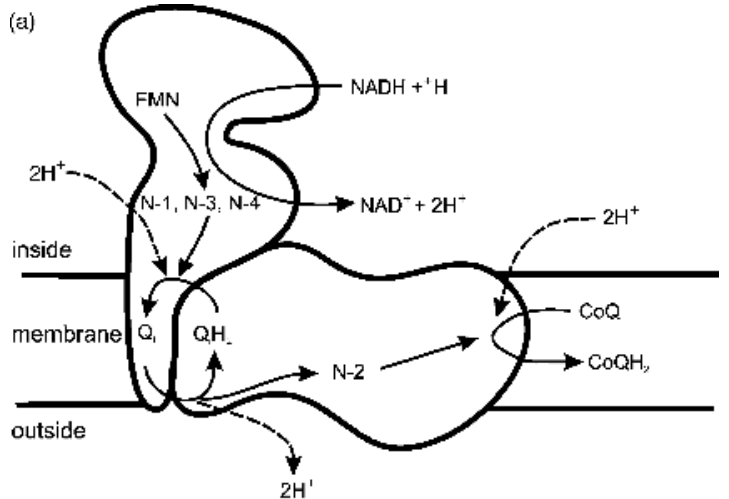

(b) N1a O

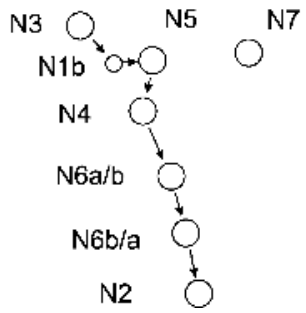

Figure 1.9 (a) Schematic of the NADH-CoQ reductase complex (complex I) showing the organisation of the redox sites. $\mathrm{N}-1, \mathrm{~N}-2$, $\mathrm{N}-3$ and N-4 are iron sulfur clusters, $\mathrm{Q}_{\mathrm{i}}$ is an internal quinone, FMN is flavin mononucleotide and CoQ is coenzyme Q. The full arrows show the direction of electron transfer and the broken arrows the direction of proton transfer (based on Hofhaus et al. [14]). (b) The arrangement of the electron transfer chain in the hydrophilic (peripheral) arm of the complex (based on Hinchcliffe and Sazanov [16]. N1a and N1b are two iron two sulfur clusters; N2, N3, N4, N5, N6a/b, N6b/a and N7 are four iron four sulfur clusters. The suggested electron transport pathway is shown by the arrows.

A recent study by Hinchliffe and Sazanov [16] has found a chain of eight iron-sulphur clusters in the hydrophilic domain of the complex with edge-to-edge spacings of less than $1.4 \mathrm{~nm}$ with the ninth iron-sulfur cluster somewhat further away (Figure 1.9b). The eight iron-sulfur clusters form an electron transport chain $8.4 \mathrm{~nm}$ long, which is believed to connect the two catalytic sites of the enzyme. Reduction of coenzyme Q occurs at the part of the protein complex which is within the membrane. Overall the reaction of one molecule of $\mathrm{NADH}$ generates one molecule of reduced coenzyme Q and, it is suggested, pumps four protons across the membrane

$$
\mathrm{NADH}+\mathrm{CoQ}+5 \mathrm{H}_{\text {inside }}^{+} \rightarrow \mathrm{NAD}^{+}+\mathrm{CoQH}_{2}+4 \mathrm{H}_{\text {outside }}^{+}
$$

Here the subscripts 'inside' and 'outside' refer to the location of the proton with respect to the inner mitochondrial membrane. At present there is not a crystal structure for the NADH-CoQ reductase complex and the precise pathway of electron transfer within the complex and the mechanism and stoichiometry of proton transport are currently not well established, although a crystal structure of the hydrophilic domain of complex I from Thermus thermoplilus has recently been obtained [17]. For further details of the NADH-CoQ reductase complex, readers are directed to several recent reviews [13,18-21].

\subsubsection{The Succinate-CoQ Reductase Complex}

The succinate-CoQ reductase complex, also referred to as complex II, spans the mitochondrial membrane, but does not pump protons across it - the free energy released by the reaction of succinate with coenzyme Q is insufficient to drive the transfer of a proton across the membrane [11]. The complex comprises two hydrophilic sub-units and one or two hydrophobic sub-units, which are associated with the membrane [22-24]. Succinate reacts at a flavin, $\mathrm{FAD}$, prosthetic group in one of the hydrophilic sub-units, of the complex located on the inside of the membrane. From here the electrons are passed one at a time to iron-sulfur centres and thus to the coenzyme $\mathrm{Q}$ reduction site (Figure 1.10). Succinate-CoQ reductase complexes from some species also contain cytochrome $b_{560}$ redox sites $[22,23,25]$.

\subsubsection{The $\mathrm{CoQH}_{2}-\mathrm{Cyt} c$ Reductase Complex}

The $\mathrm{CoQH}_{2}$-cyt $c$ reductase complex, also referred to as the cytochrome $b c_{1}$ complex or complex III, is a homodimeric transmembrane protein complex that takes electrons from the reduced coenzyme $\mathrm{Q}$, produced by the NADH-CoQ reductase and succinate-CoQ reductase complexes, and passes the electrons to cytochrome $c$, a water soluble $13 \mathrm{kDa}$ electron transfer protein through the so-called Q cycle $[26,27]$. In doing so it pumps two protons across the membrane and releases another two from the reduced quinone

$$
\begin{aligned}
& \mathrm{CoQH}_{2}+2 \operatorname{cyt} c\left(\mathrm{Fe}^{3+}\right)+2 \mathrm{H}_{\text {inside }}^{+} \\
& \rightarrow \mathrm{CoQ}+2 \operatorname{cyt} c\left(\mathrm{Fe}^{2+}\right)+4 \mathrm{H}_{\text {outside }}^{+}
\end{aligned}
$$

Figure 1.11 summarises the scheme. In the complex there are three catalytic sub-units which contain two cytochrome $b$ redox centres (b-type hemes), a cytochrome $c_{1}$ redox centre and a two iron two sulfur, $\mathrm{Fe}_{2} \mathrm{~S}_{2}$, centre, respectively. 


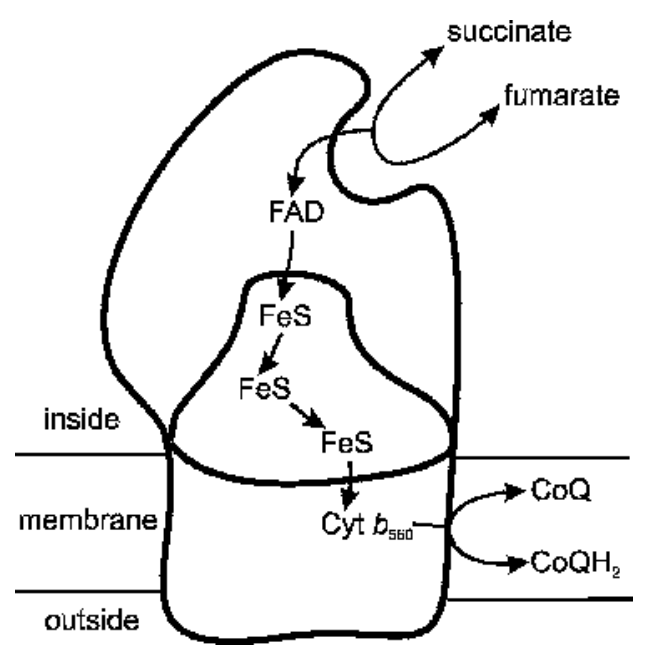

Figure 1.10 A schematic of the succinate-CoQ reductase complex (complex II) showing the organisation of the redox sites. The arrows show the direction of electron transfer. FeS are iron-sulfur clusters, FAD is flavin dinucleotide, cyt $b_{560}$ is cytochrome $b_{560}$ and $\mathrm{CoQ}$ is coenzyme Q (based on Hägerhäll and Hederstedt [23]).

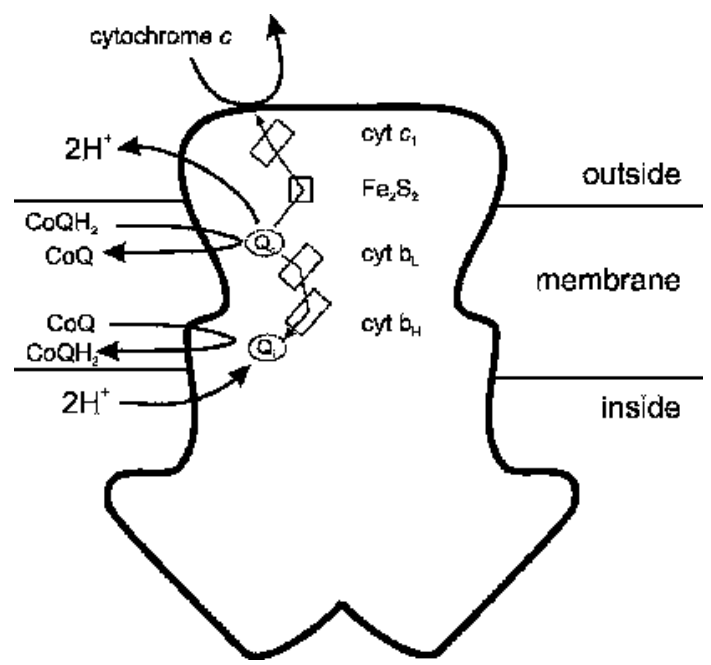

Figure 1.11 A schematic of the $\mathrm{CoQH}_{2}-$ cyt $c$ reductase complex (complex III) showing the organisation of the redox sites. The arrows show the direction of electron and proton transfer. $\mathrm{Q}_{\mathrm{o}}$ and $\mathrm{Q}_{\mathrm{i}}$ represent the coenzyme $\mathrm{Q}, \mathrm{CoQ}$, reaction sites on the outside and inside of the membrane respectively, cyt $c_{1}$, cyt $b_{\mathrm{L}}$ and cyt $b_{\mathrm{H}}$ are three cytochrome centres with $b_{\mathrm{L}}$ and $b_{\mathrm{H}}$ being the low and high potential cytochrome $b$ centres respectively, $\mathrm{Fe}_{2} \mathrm{~S}_{2}$ is a two iron, two sulfur cluster. The overall complex is a homodimer, the electron and proton transfer chains are only shown for one half for clarity.
The reduced coenzyme $\mathrm{Q}, \mathrm{CoQH}_{2}$, is oxidised in two steps with one electron being transferred to a high potential redox chain to give the semiquinone, $\mathrm{CoQ}^{\bullet}$, which then gives up a second electron to a separate low-potential redox chain in what appears to be a concerted electron transfer, since no intermediate semiquinone can be detected. In the first electron transfer the electron is transferred to the $\mathrm{Fe}_{2} \mathrm{~S}_{2}$ cluster and then to the cytochrome $c_{1}$ from where it is transferred to the soluble cytochrome $c$ electron transfer protein. This is referred to as the high-potential redox pathway, because the redox potentials of the $\mathrm{Fe}_{2} \mathrm{~S}_{2}$ cluster and the cytochrome $c_{1}$ redox centres are significantly more positive $(\sim 300 \mathrm{mV}$ vs NHE) than those of the cytochrome $b$ centres in the other pathway ( $\sim 50$ and $-70 \mathrm{mV}$ vs NHE). The second electron is transferred from the semiquinone, $\mathrm{CoQ}^{\bullet}$, to one cytochrome $b$ and then on to a second cytochrome $b$, at a site within the protein complex on the other side of the membrane, where coenzyme $\mathrm{Q}$ is reduced in two steps to $\mathrm{CoQH}_{2}$, the fully reduced form. This makes up the $\mathrm{Q}$ cycle and leads to pumping of protons across the membrane. Crystallographic studies by Zhang et al. [28] suggest that a significant conformational change in the protein is associated with this direction of the electrons from the reduced coenzyme Q [27]. In one conformation the $\mathrm{Fe}_{2} \mathrm{~S}_{2}$ cluster is close enough to the coenzyme $\mathrm{Q}$ binding site to pick up an electron. In the second conformation the $\mathrm{Fe}_{2} \mathrm{~S}_{2}$ cluster swings away from the coenzyme $\mathrm{Q}$ binding site, moving through about $1.6 \mathrm{~nm}$, and approaches close enough to the cytochrome $c_{2}$ heme to allow electron transfer. At the same time the $\mathrm{Fe}_{2} \mathrm{~S}_{2}$ cluster is too far from the coenzyme Q binding site to collect the second electron, which is therefore passed to the heme of the cytochrome $b$. For a discussion of possible short circuits between these two pathways in the Q cycle see Osyczka et al. $[29,30]$.

The crystal structures of $\mathrm{CoQH}_{2}-$ cyt $c$ reductase complexes from several organisms have been solved at high resolution [28,31], so that we know quite a lot about the relative organisation and distances between the redox groups within the protein.

\subsubsection{The Cyt $c$ Oxidase Complex}

The cyt $c$ oxidase complex, or complex IV, is the terminus for the mitochondrial electron transport and the site for the reduction of molecular oxygen to water [32-36]. The mitochondrial complex has 13 sub-units, two of which have catalytic functions, while the others are involved in the binding of the active sub-units and a lipid molecule [37-39]. The first of the catalytic sub-units contains an unusual $\mathrm{Cu}$ centre with two $\mathrm{Cu}$ atoms, which is thought to be the reaction site for the cytochrome $c$. The second of the catalytic 


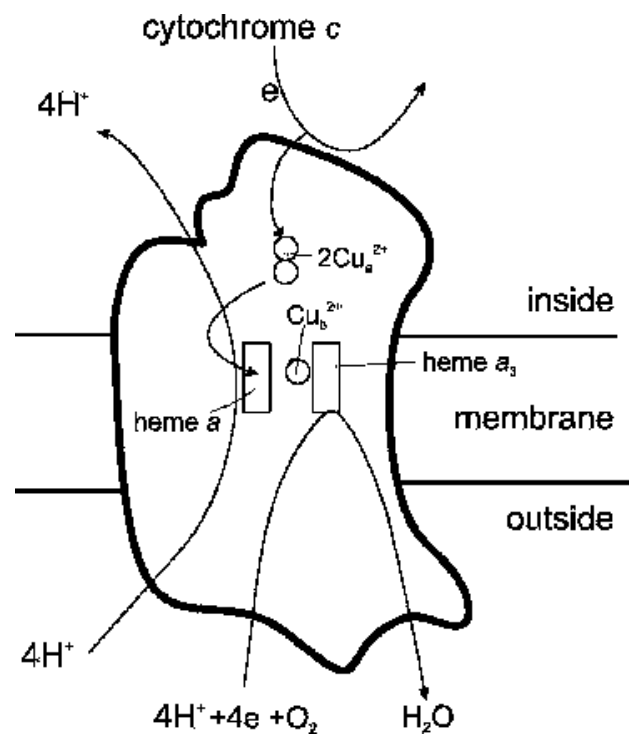

Figure 1.12 A schematic of the cyt $c$ oxidase complex (complex IV) showing the organisation of the redox sites. Hemes $a$ and $a_{3}$ are the two heme centres associated with the copper b site, $\mathrm{Cu}_{\mathrm{b}}{ }^{2+}$; $\mathrm{Cu}_{\mathrm{a}}{ }^{2+}$ are the two copper a centres (based on Faxén et al. [40]).

sub-units contains two type- $a$ heme centres; one of these accepts electrons from the first sub-unit. The second type- $a$ heme forms part of a binuclear centre with a $\mathrm{Cu}$ centre. This binuclear $\mathrm{Cu} /$ heme- $a$ centre is the site for oxygen reduction (Figure 1.12). Transfer of electrons from the reduced cytochrome $c$, produced by the $\mathrm{CoQH}-\mathrm{cyt} c$ reductase complex, through the Cyt $c$ oxidase complex to molecular oxygen, leads to the transfer of a further two protons across the inner mitochondrial membrane for every pair of electrons transferred

$$
\begin{aligned}
& 2 \text { cyt } c\left(\mathrm{Fe}^{2+}\right)+4 \mathrm{H}_{\text {inside }}^{+}+{ }^{1} / 2 \mathrm{O}_{2} \\
& \quad \rightarrow 2 \text { cyt } c\left(\mathrm{Fe}^{3+}\right)+\mathrm{H}_{2} \mathrm{O}+2 \mathrm{H}_{\text {outside }}^{+}
\end{aligned}
$$

The precise molecular mechanism by which the protons are pumped across the membrane has been investigated by Faxén et al. [40].

From an electrochemical perspective, the detailed mechanism of the reduction of molecular oxygen to water by the cyt $c$ oxidase complex is of particular interest, since the design of efficient catalysts for four electron reduction of oxygen at neutral $\mathrm{pH}$ remains a very significant impediment to the development of PEM fuel cells. At present, although crystal structures have been obtained for cyt $c$ oxidase complexes, the resolution is not sufficient to

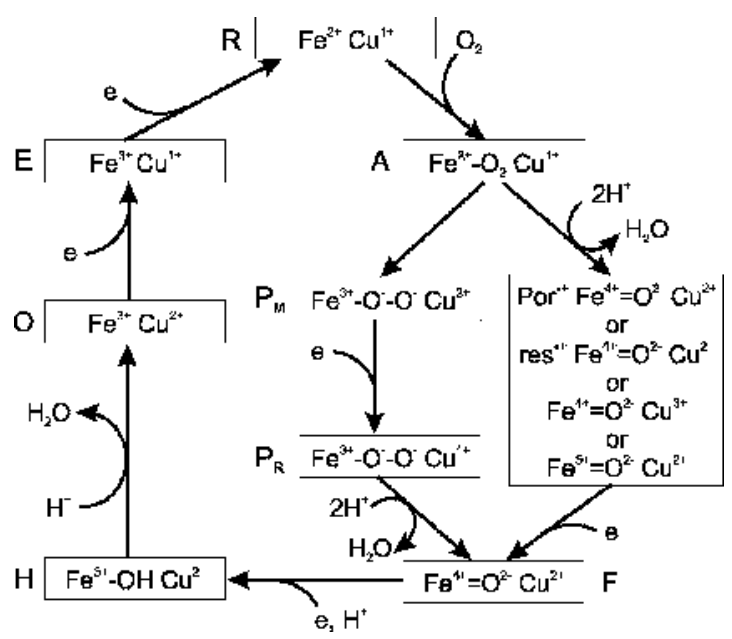

Figure 1.13 The mechanism for oxygen reduction in the cyt $c$ oxidase complex proposed by Michel et al. [35]. O is the oxidised form, $\mathrm{E}$ the one-electron reduced form, $\mathrm{R}$ the two-electron reduced form, and $A$ the product formed on oxygen binding. $P_{M}$ and $P_{R}$ are peroxy intermediates, alternative structures are given in the box on the right assuming that the $\mathrm{O}-\mathrm{O}$ bond is already broken in these states; the missing electron could be provided by a porphyrin ring $\left(\right.$ Por $\left.^{\bullet+}\right)$, an amino acid residue $\left(\mathrm{res}^{\bullet+}\right)$, a copper b site $\left(\mathrm{Cu}^{3+}\right)$, or the heme $a_{3}-\mathrm{Fe}\left(\mathrm{Fe}^{5+}\right) . \mathrm{F}$ is the oxyferryl state and $\mathrm{H}$ the hydroxyl state formed after protonation of the iron-bound oxygen.

fully define the geometry of the oxygen binding site. Furthermore the X-ray structures show only a snapshot of the structure and cannot reveal the dynamics of protein movement during the catalytic cycle. Two mechanisms have been proposed to describe oxygen reduction by the binuclear $\mathrm{Cu} / \mathrm{heme}-a$ site. As shown in Figure 1.13, Michel et al. [35] suggest that the oxygen binds to the heme iron (A) and then forms a peroxy intermediate $\left(\mathrm{P}_{\mathrm{M}}\right)$, by transfer of an electron from the $\mathrm{Cu}$, followed by the addition of a second electron and two protons to produce an oxoferryl state $(\mathrm{F})$. Further addition of a proton and electron gives a hydroxy state $(\mathrm{H})$. Protonation and two further electron transfers return the system to the starting, doubly reduced state (R). Michel et al. also suggest that there could be an alternative route if one assumes that the $\mathrm{O}=\mathrm{O}$ bond is broken at an earlier stage. In this case there are several possibilities for the intermediate species, as shown in the box in Figure 1.13, depending on where the additional electron is taken from. In contrast, Wikström [41] has proposed a different mechanism in which the two peroxy intermediates, $\mathrm{P}_{\mathrm{R}}$ and $\mathrm{P}_{\mathrm{M}}$, correspond to ferryl, $\mathrm{Fe}(\mathrm{IV})$, species where the additional electron is provided by a nearby tyrosine (YOH) (Figure 1.14). In both cases the close proximity of the heme iron and the $\mathrm{Cu}$, 


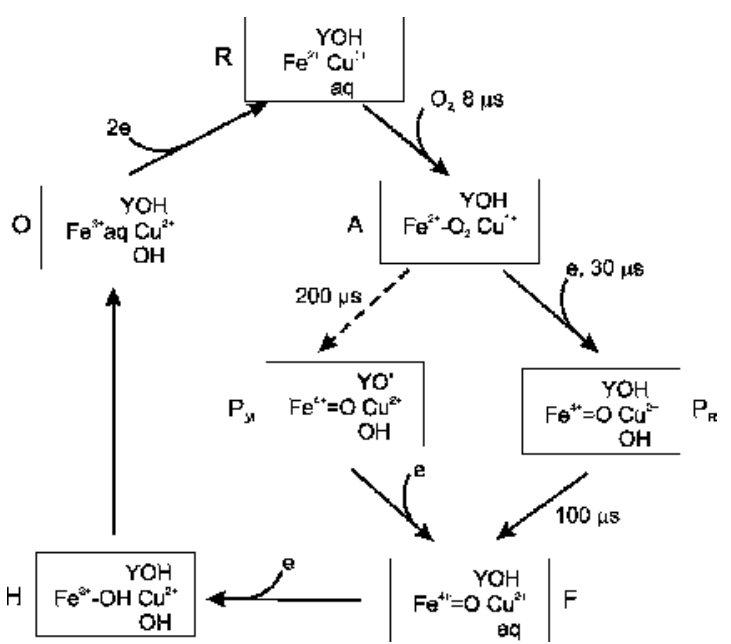

Figure 1.14 The mechanism for oxygen reduction in the cyt $c$ oxidase complex proposed by Wikström [41]. The boxes represent the binuclear centre with the nearby tyrosine residue ( $\mathrm{YOH})$. $\mathrm{O}$ is the oxidised form, $\mathrm{R}$ the two-electron reduced form, A the product formed on oxygen binding and $\mathrm{P}_{\mathrm{M}}$ and $\mathrm{P}_{\mathrm{R}}$ are peroxy intermediates.

they are within $0.52 \mathrm{~nm}$ of each other, is important for the catalysis.

\subsubsection{Electron Transport Chains in Bacteria}

In comparison to mitochondria, bacteria tend to contain redundant electron transport systems [42]. As a result, bacteria can grow under a variety of conditions and can switch between different branches of their electron transport chains depending upon the conditions. Bacteria utilize a range of electron donors in energy generation, together with either oxygen as the ultimate electron acceptor, in aerobic respiration, or other species such as $\mathrm{NO}_{3}{ }^{-}$or $\mathrm{SO}_{4}{ }^{2-}$, in anaerobic respiration, although in these cases less energy is generated. The electron transport chains in bacteria are very similar to those in the mitochondrion and the principles are the same [43], although the polypeptide composition of the electron transport proteins in bacteria is usually simpler than those in mitochondria and the proteins involved are located in the cell membrane itself (prokaryotes do not contain separate mitochondria). Sequential electron transfers between different components in the electron transport chain leads to the pumping of protons across the membrane. This establishes a proton motive force which the cell uses to synthesise ATP from ADP. In addition, the different protein complexes and prosthetic redox centres are closely related to those of the mitochondrion, although

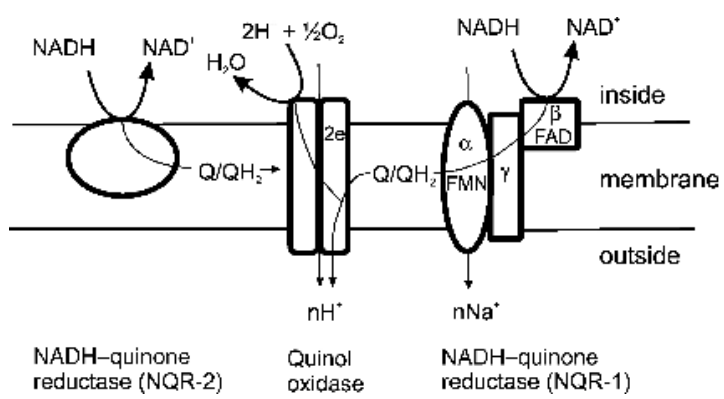

Figure 1.15 The respiratory electron transport chain of marine Vibrio based on the work of Unemoto [45]. Q is ubiquinone, FNM is flavin mononucleotide and FAD is flavin dinucleotide.

there are differences in the detailed structures. In fact, this is not surprising since it is now accepted that the mitochondria found in eukaryotes arose more than 1 billion years ago when an energetically inefficient eukaryotic cell was invaded by a more energy efficient bacterium, a process called endosymbiosis. Subsequent transfer of much of this bacterial genetic information to the nucleus of the eukaryotic cell led to the invading symbiotic bacterium being transformed into the structure we know today as the mitochondrion [44]. As a consequence, mitochondrial DNA (mtDNA) which codes for the four respiratory complexes (I to IV) and the ATP synthase found in the mitochondrial membrane, is distinct from the rest of the DNA of the organism, uses a different DNA code, and is strictly maternally inherited $[7,44]$.

As an illustration, Figure 1.15 shows the respiratory chain of marine Vibrio [45]. Notice, in this case, that there are three main complexes, an NADH-quinone reductase, a quinol oxidase, and an NADH-quinone reductase. These are linked together by quinones. In this case, the organism pumps both $\mathrm{H}^{+}$and $\mathrm{Na}^{+}$across the membrane to generate both a proton motive force and a transmembrane difference in the electrochemical potential of $\mathrm{Na}^{+}$.

Escherichia coli is able to assemble specific respiratory chains by the synthesis of the necessary dehydrogenase and reductase enzymes in response to the conditions in which it finds itself. As an example, Figure 1.16 shows an electron transport chain for Escherichia coli during anaerobic respiration $[46,47]$. In this case, nitrate replaces oxygen as the ultimate electron acceptor.

\subsubsection{Electron Transfer in Photosynthesis}

A very similar situation pertains in photosynthesis as in the mitochondrial electron transport chain, except that this time the energy is provided by light rather than by 
lactate dehydrogenase

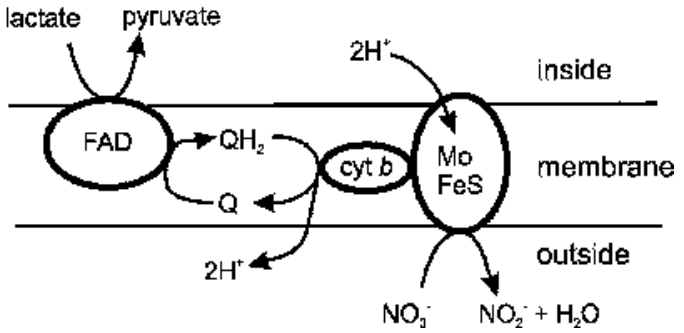

Figure 1.16 The electron transport chain for Escherichia coli during anaerobic respiration (based on Smith and Wood [70], Dym et al. [47] and Bertero et al. [46]). FAD is flavin, FeS are iron-sulfur clusters, $\mathrm{Q}$ is menaquinone, cyt $b$ is a $b$-type cytochrome and Mo is molybdopterin-guanosine-dinucleotide.

glucose. However, the molecular organisation and the structures of many of the components involved are very similar, and the governing principle, that sequential electron transfers lead to the generation of a proton motive force across the energy transducing membrane by pumping protons across the membrane, remains the same. In this section we will look at the photosynthetic electron transport chain found both in plants and bacteria. Again, as in respiration, the proton motive force set up by the photosynthetic membrane is used to drive the formation of ATP from ADP.

In plants, photosynthesis occurs in the chloroplasts. These are large organelles found mainly in the leaf cells of the plant. The principle products of the photosynthetic metabolism of carbon dioxide are $\mathrm{C}_{6}$ sugars in the form of sucrose and starch. The sucrose is water soluble and is transported from the chloroplast to other parts of the plant to provide energy for metabolism. The starch is stored within the leaf.

The chloroplast (Figure 1.17) has three membranes. The outermost membrane of the chloroplast, as with the mitochondrion, contains a large number of porin proteins, which make it readily permeable to low molecular weight species, such as sucrose. Inside this, the second membrane is the primary permeability barrier of the chloroplast and contains various permeases, proteins which control ingress and egress of species from the chloroplast interior. Unlike the mitochondrion, the energy transducing membrane of the chloroplast, called the thylakoid membrane, is separate from the inner membrane of the organelle. The thylakoid membrane is where the chlorophyll is located and is the site of energy conversion. Again, note that as for the mitochondrion, the thylakoid membrane totally encloses a volume of solution, called the lumen, within

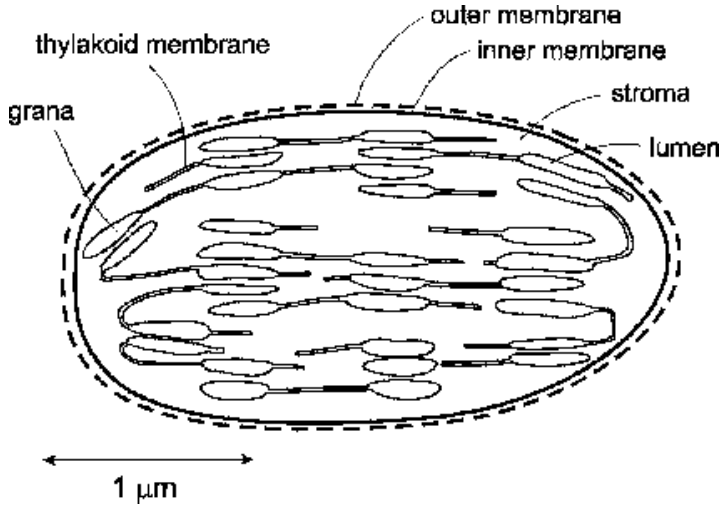

Figure 1.17 The structure of the chloroplast.

the chloroplast, so that a proton motive force can be generated across the membrane during photosynthesis. Within the chloroplast these thylakoid membranes frequently form flattened, pancake-like structures, called grana, which then form into stacks.

The thylakoid membrane in algae and higher plants contains two photosystems referred to as photosystem I and photosystem II or PS I and PS II. Both photosystems contain chlorophyll and under irradiation, the absorption of light within the photosystem leads to charge separation across the thylakoid membrane, with positive charge being drive to the lumen side of the membrane and negative charge to the stroma side of the membrane. The stroma side is the side of the thylakoid membrane which is on the outside - that is the solution contained within the chloroplast. Photochemically driven charge separation in photosystems I and II is coupled together by a quinone cycle and a cytochrome $b f$ complex (Figure 1.18). Overall the photochemically driven reaction is

$$
2 \mathrm{H}_{2} \mathrm{O}+2 \mathrm{NADP}^{+}+2 \mathrm{H}_{\text {outside }}^{+} \stackrel{h v}{\longrightarrow} \mathrm{O}_{2}+2 \mathrm{NADPH}+4 \mathrm{H}_{\text {inside }}^{+}
$$

where electrons are transferred from water to $\mathrm{NADP}^{+}$. This reaction is essentially the reverse of the reaction of respiration in the mitochondrion (NADPH is closely related in structure to NADH, see below). The measured values for the quantum requirement (that is the number of photons required for each molecule of oxygen produced) in intact leaves, under ideal conditions, are typically nine or ten, close to the theoretical value of eight with one photon absorbed by each of the two photosystems for each 


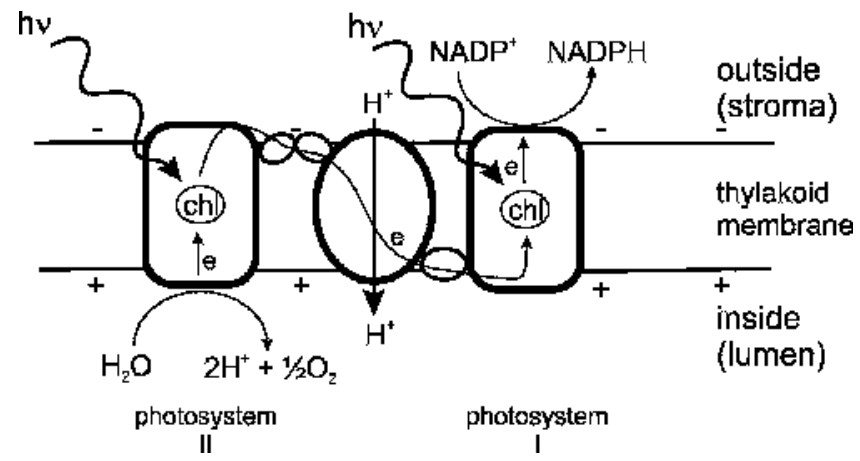

Figure 1.18 The overall scheme for the photosynthetic electron transfer pathway showing the two photosystems, photosystem I and photosystem II, and the direction of electron and proton transfer. $\mathrm{NADP}^{+}$is nicotinamide adenine dinucleotide phosphate and chl is chlorophyll.

electron transported along the chain [6]. This photochemical reaction generates a proton motive force across the thylakoid membrane in which the inside, lumen, is positive. This proton motive force is used by the $\mathrm{CF}_{0} \mathrm{CF}_{1}$ complex, a large transmembrane protein complex embedded in the thylakoid membrane, to generate ATP from ADP in much the same way that the $F_{0} F_{1}$ ATPase complex in the mitochondrion generates ATP (see below). The ATP and NADPH generated by the photochemically driven reactions are used within the chloroplast to fix carbon dioxide and produce sugars

$$
\begin{aligned}
& 6 \mathrm{CO}_{2}+18 \mathrm{ATP}^{4-}+12 \mathrm{NADPH}+12 \mathrm{H}_{2} \mathrm{O} \\
& \stackrel{h v}{\longrightarrow} \mathrm{C}_{6} \mathrm{H}_{12} \mathrm{O}_{6}+18 \mathrm{ADP}^{3-}+12 \mathrm{NADP}^{+}+18 \mathrm{HPO}_{4}{ }^{2-}+6 \mathrm{H}^{+}
\end{aligned}
$$

The overall efficiency for this process, calculated in terms of the energy stored over the energy absorbed in the form of light, comes out at about $27 \%$ [6].

In this section we will focus specifically on the electron transfer reactions which occur within the thylakoid membrane; those who would like to know more about the photochemical, as distinct from the electrochemical, processes which accompany photosynthesis are directed to an excellent recent text by Blankenship [6]. Figure 1.19 shows the different components in the electron transport chain of the thylakoid electron transport chain $[2,48-50]$.

The process of photosynthesis begins with the absorption of light by the light harvesting complex of photosystem II. This energy is passed to the photoreaction centre of photosystem II where it drives charge separation across the thylakoid membrane leading to the oxidation of water

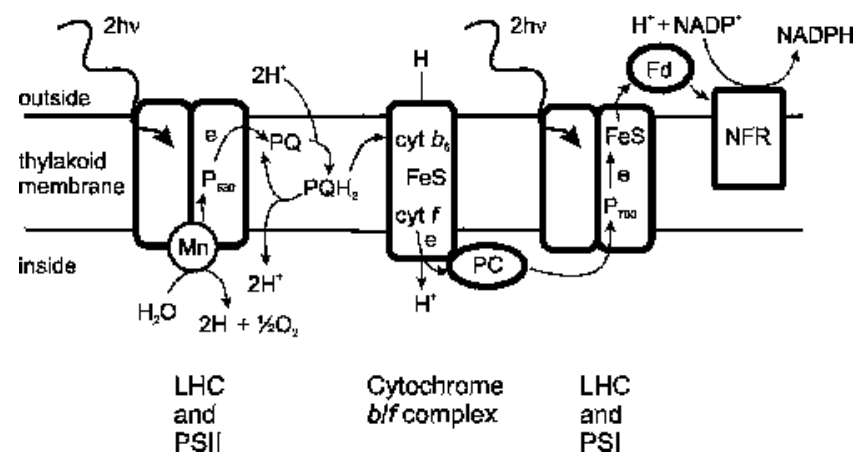

Figure 1.19 The different components of the photosynthetic electron transfer pathway, showing the light harvesting complexes, LHC, and photosystems, PS. The arrows show the direction of electron and proton transfer. PQ is plastoquinone, PC is plastocyanin, Fd is flavodoxin, PS I and PS II are photosystem I and II respectively, NFR is ferredoxin-NADP oxidoreductase, $\mathrm{P}_{600}$ and $\mathrm{P}_{700}$ are the reaction centre chlorophylls, $\mathrm{Mn}$ is the four manganese oxygen evolving complex, cyt $f$ and cyt $b$ are cytochromes, FeS is an iron-sulfur cluster and FAD is flavin adenine dinucleotide. 
to molecular oxygen, the generation of a reduced molecule of ubiquinone (the equivalent of coenzyme $\mathrm{Q}$ in the plant system) and the translocation of protons across the membrane. The reduced ubiquinone $\left(\mathrm{QH}_{2}\right)$ passes the electrons to the cytochrome bf complex and hence to plastocyanin, a water-soluble electron transfer protein with a single $\mathrm{Cu}^{+/ 2+}$ redox site. At the same time protons are pumped across the membrane. From plastocyanin the electrons are passed to photosystem I, where further absorption of light drives electron transfer across the membrane and the reduction of $\mathrm{NADP}^{+}$to NADPH.

Photosystems I and II both have light-harvesting complexes associated with them, but the two are structurally different and are located in different parts of the thylakoid membrane. Photosystem II and its associated light-harvesting complex is located mainly in the stacked grana membranes, whereas photosystem $\mathrm{I}$ and the $\mathrm{CF}_{0} \mathrm{CF}_{1}$ complex are located in the parts of the membrane, the stroma, which link together the grana. The cytochrome $b f$ complex is found in both grana and stroma membranes [51]. Since the photosystems are located in physically separate parts of the thylakoid membrane, relatively long range (tens of $\mathrm{nm}$ ) diffusive transport of electrons by the plastoquinone associated with the membrane and the plastocyanin in the lumen play an important part in the overall process.

Comparing the overall picture shown in Figure 1.19 for photosynthesis with that for the mitochondrial electron transport chain, Figure 1.8, reveals some significant similarities. Thus, quinone redox species, either coenzyme $\mathrm{Q}$ or plastoquinone, play an important role in proton transfer across the membrane; water soluble one-electron transfer proteins, either cytochrome $c$ or plastocyanin, are used to couple together electron transfer between large transmembrane proteins, and, as we shall see below when we consider the components of the photosynthetic electron transport chain in more detail, there are striking similarities between the $\mathrm{CoQH}_{2}-\mathrm{cyt} c$ reductase complex in mitochondria and the cytochrome bf complex in photosynthesis. These significant similarities in the operation of the two major energy transducing systems in biology strongly suggest a common evolutionary origin.

\subsubsection{Photosystem II}

Photosystem II is a multisub-unit protein complex which is found embedded in the thylakoid membranes of higher plants as well as algae and cyanobacteria [52,53]. Associated with photosystem II there is a light-harvesting complex, which contains an array of chlorophyll a, chlorophyll $\mathrm{b}$ and carotenoid pigments (Figure 1.20) [54-56]. The role of the light-harvesting complex is to capture the energy from incoming light and funnel it to the photoreaction centre where charge separation occurs, it also has a role in the non-radiative dissipation of excess excitation energy to protect the system from damage at high light levels. The light-harvesting complex is necessary because, even in full sunlight, the light falling on the plant leaf represents a fairly dilute energy source [6]. The different pigments in the light-harvesting complex pigments have the effect of extending the range of wavelengths of light that the plant can absorb. When light is absorbed by the pigment array of the light-harvesting complex, the energy is passed by rapid resonant energy transfer in less than $1 \mathrm{~ns}$ to a pair of the chlorophyll a pigments in the photoreaction centre of photosystem II. This special pair of chlorophyll a molecules, $\mathrm{P}_{680}$, play a central role in energy transduction in photosystem II, because it is at this stage that charge separation occurs (Figure 1.21).

The Photosystem II photoreaction centre contains these two special chlorophyll a molecules $\left(\mathrm{P}_{680}\right)$ together with two other chlorophylls, two pheophytin molecules (pheophytin is a metal-free chlorophyll, where the $\mathrm{Mg}^{2+}$ is replaced by two protons) and two quinones, all arranged to form an efficient electron transport chain [55,57-61]. Absorption of a photon with wavelength below $680 \mathrm{~nm}$ (corresponding to an energy of $176 \mathrm{~kJ} \mathrm{~mol}^{-1}$ ) generates the oxidised form of the chlorophyll a, $\mathrm{P}_{680}{ }^{+}$, by electron transfer via pheophytin and a quinone to the terminal quinone acceptor molecule on the outer surface of the thylakoid membrane. The $\mathrm{P}_{680}{ }^{+}$is reduced by electron transfer from the oxygen evolving complex of photosystem II located on the inner side on the thylakoid membrane. This oxygen evolving complex contains a cluster of four manganese ions as well as bound chloride and calcium ions. The oxidation of water to molecular oxygen is a four-electron process

$$
2 \mathrm{H}_{2} \mathrm{O}+4 \mathrm{e} \rightarrow \mathrm{O}_{2}+4 \mathrm{H}^{+}
$$

The cluster of four manganese ions in the oxygen evolving complex therefore cycles through four different oxidation states in order to couple the one-electron transfer to $\mathrm{P}_{680}{ }^{+}$ to the four-electron oxidation of water [62]. The precise details of the structure of the oxygen evolving complex remain the subject of debate $[55,59]$. With the oxidation of one molecule of water to oxygen four protons are released on the inside of the membrane. Thus, photosystem II takes in energy from the light absorbed by the light-harvesting complex and uses it to produce oxygen and pump protons across the thylakoid membrane contributing to the proton motive force across the membrane. 

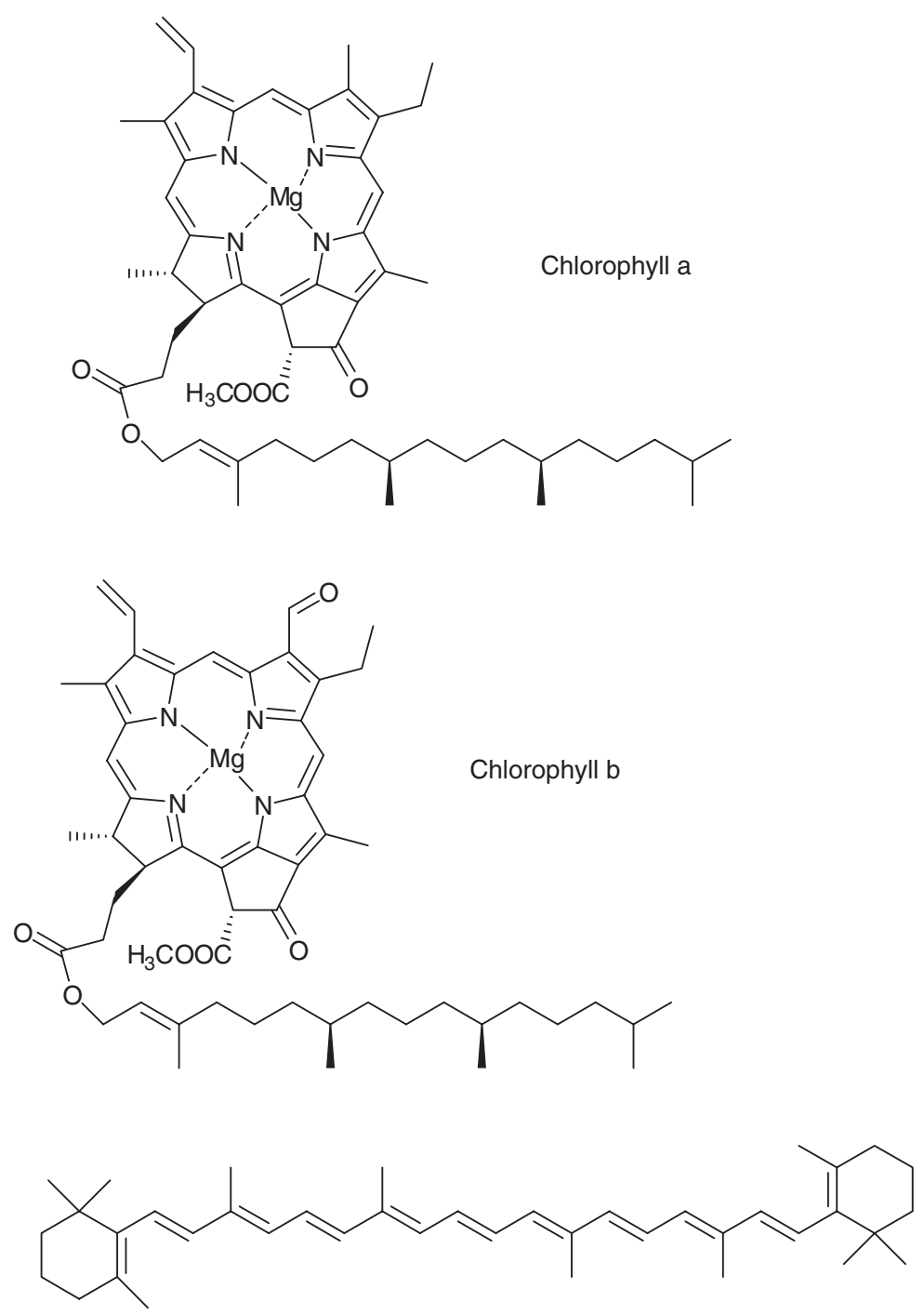

$\beta$-carotene

Figure 1.20 Structures of the light-harvesting pigments.

\subsubsection{Cytochrome bf Complex}

The cytochrome bf complex transfers electrons from photosystem II to photosystem I by catalysing the oxidation of reduced plastoquinone by plastocyanin, Pc

$$
\mathrm{QH}_{2}+2 \mathrm{Pc}^{+} \rightarrow \mathrm{Q}+2 \mathrm{Pc}+2 \mathrm{H}_{\text {outside }}^{+}
$$

In some cases, this reaction is accompanied, as in the corresponding reaction of the mitochondrial $\mathrm{CoQH}_{2}-\mathrm{cyt}$ $c$ reductase complex, by the pumping of two additional protons across the membrane through the operation of a $\mathrm{Q}$ cycle. For the cytochrome $b f$ complex this is not always the case, however, under some circumstances it can switch to a mechanism in which the two additional protons are not pumped across the membrane [49]. 


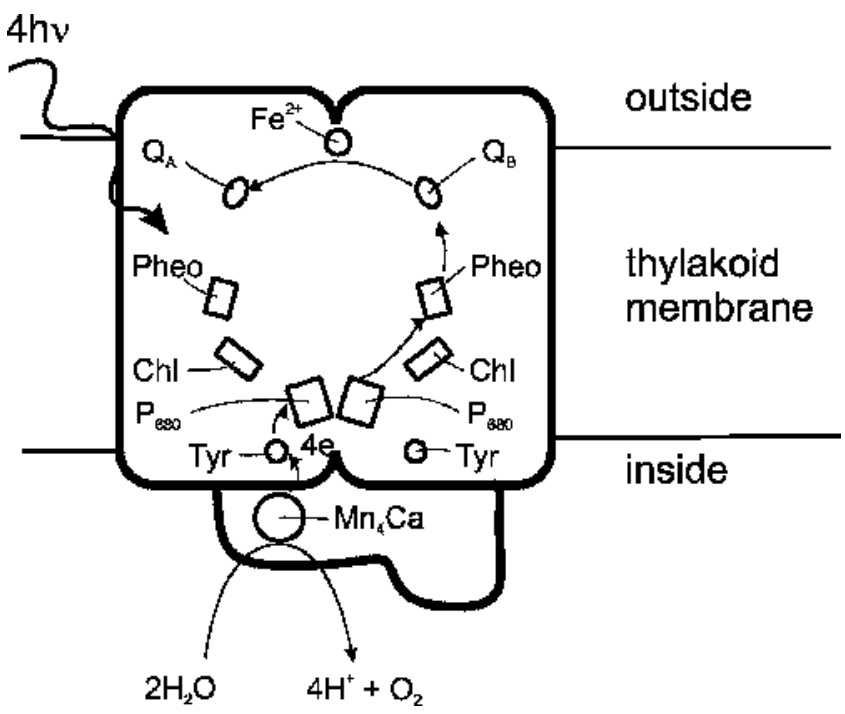

Figure 1.21 A schematic of photosystem II showing the arrangement of the redox sites (based on Loll et al. [55]). $\mathrm{Q}_{\mathrm{A}}$ and $\mathrm{Q}_{\mathrm{B}}$ are plastoquinones, $\mathrm{Chl}$ is chlorophyll, Pheo is pheophytin, $\mathrm{P}_{680}$ are a special pair of chlorophyll molecules where charge separation occurs, Tyr are tyrosine residues, $\mathrm{Mn}_{4} \mathrm{Ca}$ is the four manganese cluster of the oxygen evolving complex, $\mathrm{Fe}^{2+}$ is a non-heme iron.

The cytochrome $b f$ complex (Figure 1.22) is made up of four subunits and contains a $2 \mathrm{Fe} 2 \mathrm{~S}$ centre, two $b$-type hemes and a $c$-type heme [48]. The $2 \mathrm{Fe} 2 \mathrm{~S}$ centre is the site for oxidation of the reduced plastoquinone. The two $b$-type hemes span the hydrophobic core of the complex and are the basis of the $\mathrm{Q}$ cycle (as in the mitochondrial $\mathrm{CoQH}_{2}-$ cyt $c$ reductase complex, see above). The crystal structure of the

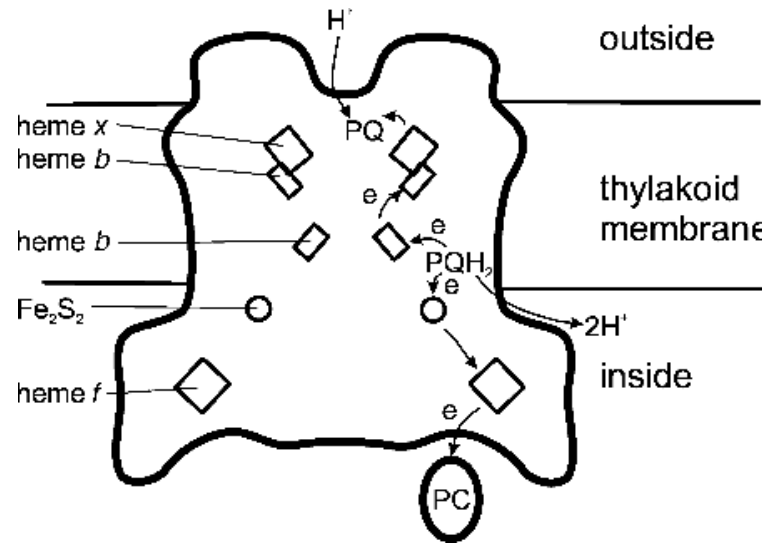

Figure 1.22 A schematic of the cytochrome $b f$ complex showing the arrangement of the redox sites (based on Kurisu et al. [63]). The enzyme is a homodimer, the electron transfer pathway is shown in one half for clarity. PC is plastocyanin, $\mathrm{PQ}$ is plastoquinone and $\mathrm{Fe}_{2} \mathrm{~S}_{2}$ is an iron-sulfur cluster. cytochrome $b_{6} f$ complex from a cyanobacterium has recently been reported [63]. However, the full details of electron transfer in the cytochrome $b f$ complex between the reduced plastoquinone and the plastocyanin are, as yet, not clear.

\subsubsection{Photosystem I}

Much of our present understanding of photosystem I is based on the crystal structure solution for photosystem I from the cyanobacterium Synechococcus elongatus, by Jordan et al. [50,58,64,65]. The core of photosystem I is substantially larger than the corresponding core of photosystem II, but despite this there is still a single pair of chlorophyll a molecules at the heart of the charge separation process. Photosystem I contains significantly more chlorophyll than photosystem II, with about 90 chlorophyll molecules associated with the light-harvesting complex and six associated with the electron transport chain.

The chlorophylls in the light-harvesting complex are arranged, along with about 20 carotenoids, in two layers (Figure 1.23). Once absorbed by the array of pigments in the light-harvesting complex, the excitation energy is rapidly passed by resonant energy transfer to a special pair of chlorophylls, $\mathrm{P}_{700}$, located in the core of the photoreaction centre, which are the start of the electron transfer chain. The absorption of this pair of chlorophylls is at $700 \mathrm{~nm}$, slightly red shifted from that in photosystem 


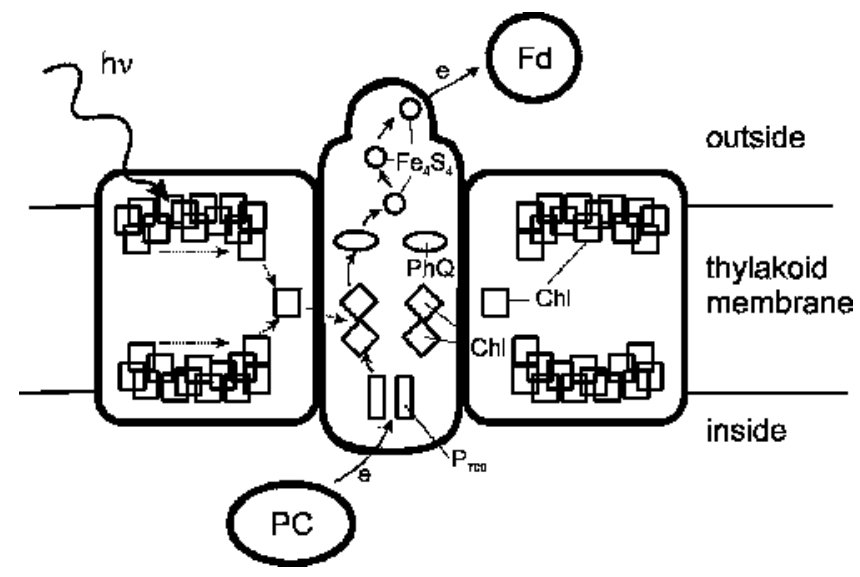

Figure 1.23 A schematic of photosystem II and its light-harvesting complex showing the arrangements of pigments and redox centres and the direction of energy (dotted arrows) and electron (solid arrows) transfers (based on Jordan et al. [64] and Kühlbrandt [65]). PC is plastocyanin, $\mathrm{Fd}$ is ferredoxin, $\mathrm{Chl}$ is chlorophyll, $\mathrm{PhQ}$ is phylloquinone, $\mathrm{Fe}_{4} \mathrm{~S}_{4}$ are iron-sulfur clusters and $\mathrm{P}_{700}$ are a special pair of chlorophylls where charge separation occurs.

II. In photosystem I charge separation occurs by electron transfer from the excited chlorophyll, $\mathrm{P}_{700}{ }^{*}$, through a chain of four accessory chlorophylls and two phylloquinones to three $4 \mathrm{Fe} 4 \mathrm{~S}$ clusters, the last of which is located on the outside of the thylakoid membrane. The chlorophylls and phylloquinones are arranged in two branches and there is still controversy over whether both branches or only one is involved in the electron transport [64]. The resulting oxidised chlorophyll, $\mathrm{P}_{700}{ }^{+}$, is reduced by plastocyanin on the inside of the membrane. Unlike photosystem II, proton transfer across the membrane does not accompany the electron transfer. From the terminal 4Fe4S cluster, the electron is transferred to ferredoxin, a small $(11 \mathrm{kDa})$ soluble one-electron redox protein containing a $2 \mathrm{Fe} 2 \mathrm{~S}$ cluster complexed to four cysteines.

The reduced ferredoxin transfers electrons to NADP reductase, a peripheral protein bound on the inside of the thylakoid membrane near photosystem I [48]. Its role is to link the one electron transfers from the ferredoxin, $\mathrm{Fd}$, to the two-electron reduction of $\mathrm{NADP}^{+}$

$$
\mathrm{NADP}^{+}+\mathrm{H}_{\text {outside }}^{+}+2 \mathrm{Fd} \rightarrow \mathrm{NADPH}+2 \mathrm{Fd}^{+}
$$

To do this the ferredoxin reductase contains a single FAD centre with two different binding sites for ferredoxin and $\mathrm{NADP}^{+}$[66]. Recent crystallographic studies of photosystem I from a higher plant have shown strong similarities in structure and in the positions of almost all of the chlorophylls with those in the cyanobacterium, despite their evolutionary divergence around 1 billion years ago [67].

\subsubsection{Bacterial Photosynthesis}

There are five different major types of bacteria: cyanobacteria, purple bacteria, green sulfur bacteria, green nonsulfur bacteria and heliobacteria, that are capable of photosynthesis [6]. Of these only one, the cyanobacteria, produce oxygen. Photosynthesis in green and purple bacteria does not generate oxygen, because they only contain one photoreaction centre, rather than the two found in green plants, cyanobacteria and algae [2]. Figure 1.24 shows the electron transport chain in purple bacteria. In this case, the process is cyclic with each cycle pumping protons across the membrane. The basic components of the chain strongly resemble those of the chloroplast discussed above [68]. Again, this similarity is not surprising, but demonstrates a common evolutionary origin; as for the mitochondrion, it is now generally accepted that the chloroplast has an endosymbiotic origin, a view supported by genetic analysis [6].

In contrast to the chloroplast, in bacteria the various components of the photosynthetic apparatus are located in the bacteria's lipid bilayer cytoplasmic membrane. In most cases this is surrounded by a second, more permeable, membrane and a tough outer cell wall to provide mechanical stability. The bacterial reaction centre captures light and uses this to drive charge separation across the bacterial membrane taking electrons from a reduced soluble cytochrome and passing on to a quinone. The resulting reduced quinone reacts with the transmembrane cytochrome $b c_{1}$ complex through a $\mathrm{Q}$ cycle leading to the pumping of protons 

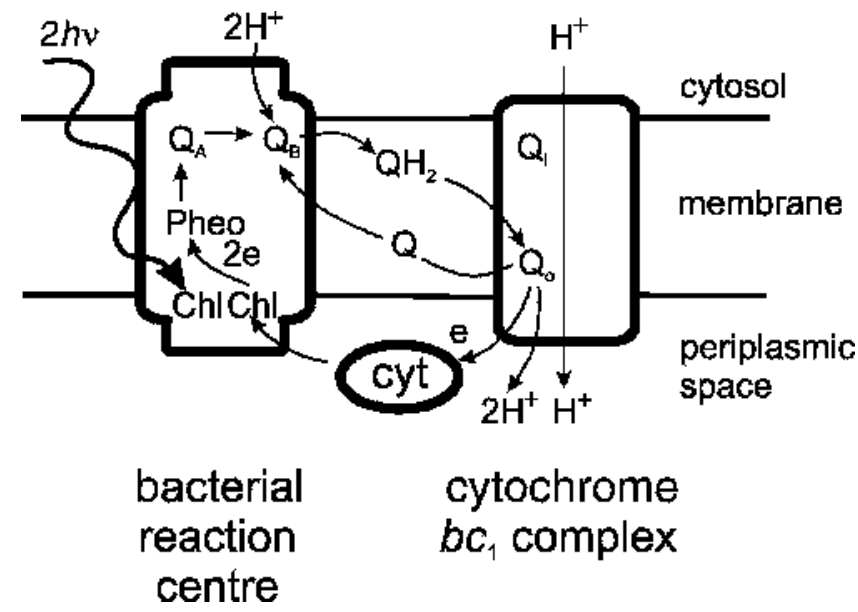

Figure 1.24 The photosynthetic electron transport chain in purple bacteria (based on [2]). $Q, Q_{A}, Q_{B}, Q_{i}$ and $Q_{o}$ are quinones, Chl are a special pair of chlorophylls, Pheo is pheophytin, Cyt is a soluble cytochrome. The associated light-harvesting complex is not shown.

across the bacterial membrane and returning the electrons to the cytochrome. The proton motive force created by this photochemically driven redox cycle is used by the bacterial $\mathrm{F}_{0} \mathrm{~F}_{1}$ complex to drive the synthesis of ATP.

Electrons can also flow through the photosynthetic electron transfer pathway of purple bacteria by a linear (as opposed to cyclic) pathway. In this case, the electrons are ultimately transferred to $\mathrm{NAD}^{+}$, generating $\mathrm{NADH}$ within the cell and pumping protons across the membrane at the same time. In this case, the electron required to reduce the oxidised chlorophyll in the photoreaction centre comes from hydrogen sulfide (producing elemental sulfur) or from hydrogen gas.

\subsection{REDOX COMPONENTS}

As we have seen in the previous sections, energy transduction in living organisms, either by photosynthesis or respiration, proceeds via a sequence of ordered electron transfer reactions which generate a proton motive force across an impermeable membrane. If is also clear from our discussion so far that there are significant similarities between the respiratory electron transport chain in prokaryotic bacteria and in the mitochondria of eukaryotic cells, and the photosynthetic electron transport chains found in green and purple bacteria and in the chloroplast. In particular, despite the apparent complexity of the different electron transport chains, nature uses a relatively limited palette of redox active centres: heme, quinones, flavins, iron-sulfur clusters, etc. In this section, we describe the structures and electrochemical reactions of these different centres.

\subsubsection{Quinones}

Quinones are two-electron, two-proton redox centres (Figure 1.25) for which the intermediate semiquinone radical is accessible and often reasonably stable so that they can undergo sequential one-electron oxidation or reduction reactions. Quinones are thus hydrogen atom carriers and the quinones involved in the energy transducing electron transport chains couple electron transport between large, transmembrane protein complexes such as photosystem II and the cytochrome $b f$ complex or the $\mathrm{NADH}-\mathrm{CoQ}$ reductase complex and the CoQ-cyt $c$ reductase complex, and transport protons across the energy transducing membrane. Because the redox reaction of the quinones involves both electrons and protons, the redox potential of the couple is $\mathrm{pH}$ dependent, shifting by $59 \mathrm{mV}$ for each unit change in $\mathrm{pH}$ at $298 \mathrm{~K}$ for the overall twoelectron, two-proton reaction.

To achieve this, all the electron transport chain quinones have a long isoprenoid chain (Figure 1.26) which makes them lipid soluble so that they can freely diffuse in the lipid membrane. In coenzyme Q (also called ubiquinone because of its ubiquity), this chain comprises between six and 10 isoprenoid units, depending on the particular organism; in humans the chain is 10 isoprenoid groups in length. The redox potential for coenzyme $\mathrm{Q}$ is $+0.100 \mathrm{~V}$ vs SHE at $\mathrm{pH}$ 7. The structure of the plastoquinones involved in photosynthesis in the chloroplast is very similar to that of coenzyme Q (Figure 1.26), with only slight changes in the substitution of the quinone ring. These changes lead to a change in the redox potential of the plastoquinones to $+0.08 \mathrm{~V}$ vs SHE. Again there is an 
<smiles>COC1=C(OC)C(=O)C(CC=C(C)CO)=C(C)C1=O</smiles><smiles>[CH]=C</smiles><smiles>CCC(C)=CCC1=C(C)C([O-])C(OC)=C(OC)C1[O-]</smiles><smiles>C=[Te][OH+]</smiles>

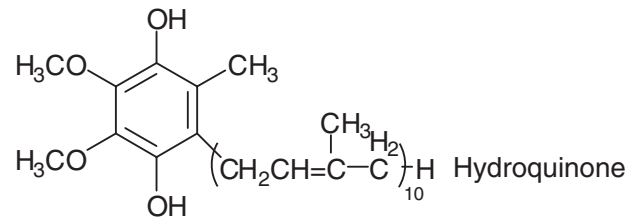

Figure 1.25 The redox reactions for quinone showing the structures of the quinone, semiquinone and hydroquinone. isoprenoid chain with between six and nine groups to ensure lipid solubility of the molecule. Some bacteria contain napthoquinones, such as menaquinone (redox potential $+0.07 \mathrm{~V}$ vs SHE at pH 7 [69]) (Figure 1.26), as well as coenzyme $\mathrm{Q}$ in their respiratory chains [70]. The principle, however, remains the same.

\subsubsection{Flavins}

Flavin adenine dinucleotide, FAD, and flavin mononucleotide, FMN, are also two-electron, two-proton redox centres [71]. The one-electron oxidation or reduction semiflavin intermediate is accessible and reasonably stable (Figure 1.27). As for the quinones, the redox potentials for flavin couples varies with $\mathrm{pH}$.

The two molecules, FAD and FMN, differ in that FAD has an additional phosphate, ribose and adenosine unit attached to the ribitol phosphate chain attached to on the flavin ring (Figure 1.28). This peripheral change, away from, and not conjugated to, the redox active part of the molecule does not alter the redox potential of the couple $(-0.21 \mathrm{~V}$ vs SCE at $\mathrm{pH} 7)$. However, the potentials of the flavin redox centre in different proteins differs widely, a point we return to below.

\subsubsection{NAD(P)H}

$\beta$-Nicotinamide adenine dinucleotide, $\mathrm{NAD}^{+}$, and $\beta$ nicotinamide adenine dinucleotide phosphate, $\mathrm{NADP}^{+}$,<smiles>CC(C)=CCCC1=C(C)C(=O)c2ccccc2C1=O</smiles>

menaquinone, $n=4-3$<smiles>[3H]CC(C)=CCC1=C(C)C(=O)C(OC)=C(OC)C1=O</smiles>

ubiquinone<smiles>[3H]CC(C)=CCC1=CC(=O)C(C)=C(C)C1=O</smiles>
plastoquinone, $n=6-9$

Figure 1.26 The structures of three quinones which are important components of electron transport chains. 
<smiles>Cc1cc2nc3c(=O)[nH]c(=O)nc-3n(P)c2cc1C</smiles>

FAD

$$
\mathrm{e}+\mathrm{H}^{+}
$$<smiles></smiles>

Semiquinone<smiles>C=[PH2+][PH3+]</smiles><smiles>Cc1cc2c(cc1C)N(P)c1[nH]c(=O)[nH]c(=O)c1N2</smiles>

$\mathrm{FADH}_{2}$

Figure 1.27 The redox reaction of flavin adenine dinucleotide. are two-electron, one-proton redox couples for which the intermediate radical forms are not readily accessible (Figure 1.29). NADH and NADPH act as hydride carriers in the biological system and generally undergo oxidation by hydride transfer in a single step. This hydride transfer can occur either to or from the alpha or beta face of the molecule. The choice of the particular face is determined by the binding of the NAD $(\mathrm{P})$ within the active site of the enzyme, and is different for different enzymes.

$\mathrm{NAD}^{+}$and $\mathrm{NADP}^{+}$differ in that $\mathrm{NADP}^{+}$has an additional phosphate on the ribose ring of the adenosine. Again, this is sufficiently removed from, and not conjugated to, the redox centre within the molecule, so that the redox potentials of the two couples are the same. The change does, however, significantly affect the binding of the different molecules to proteins and, consequently, $\mathrm{NADH}$ and NADPH perform separate functions within living cells.

The redox potential for the NAD $(\mathrm{P})^{+} / \mathrm{NAD}(\mathrm{P}) \mathrm{H}$ couple is $-320 \mathrm{mV}$ vs SHE at $\mathrm{pH} 7$. Since the reaction involves two electron and one proton this potential shifts by $29.5 \mathrm{mV}$ for each unit change in $\mathrm{pH}$ at $298 \mathrm{~K}$.

\subsubsection{Hemes}

The heme redox centre (also spelt haem) is a porphyrin ring, comprising four pyrrole rings linked by methylene bridges, with a single $\mathrm{Fe}$ ion coordinated in the centre. The different heme types, $a, b$ and $c$ differ in the substitution
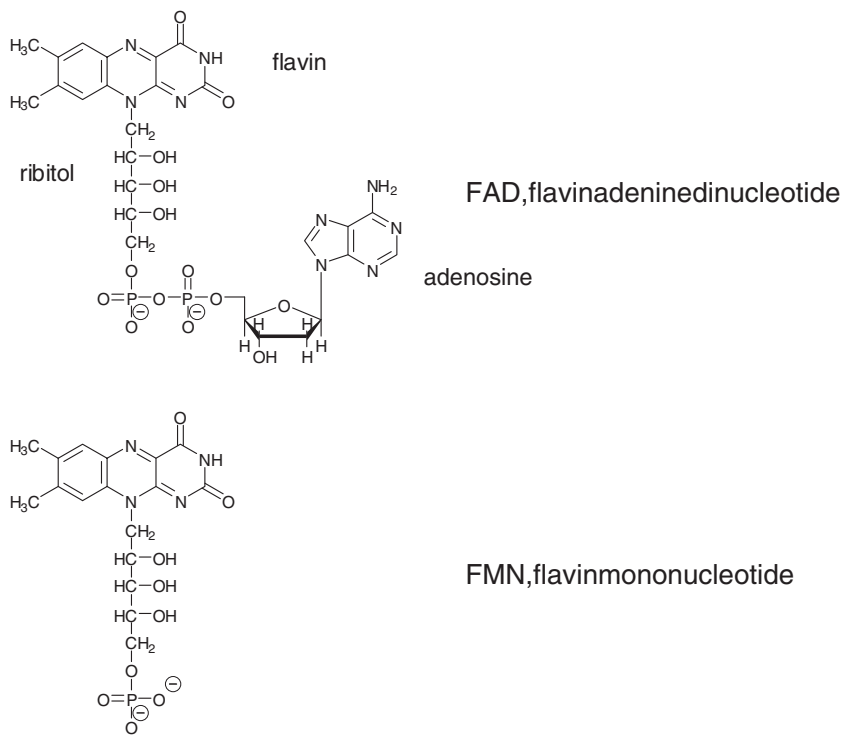

FMN,flavinmononucleotide

Figure 1.28 The structures of flavin adenine dinucleotide, FAD, and flavin adenine mononucleotide, FMN. 


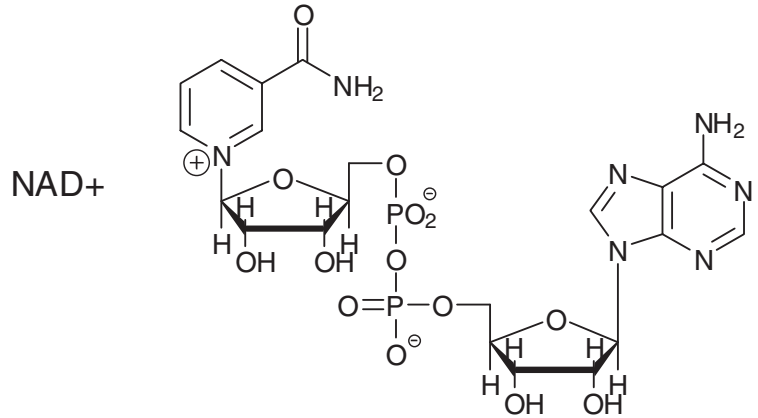

$\mathrm{NADH}$

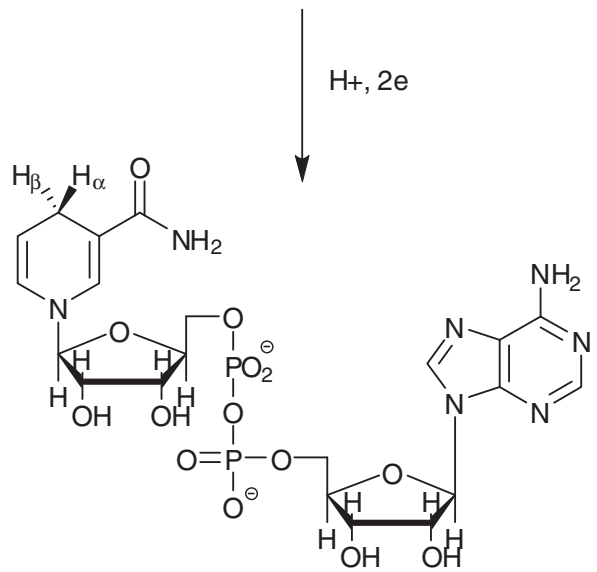

Figure 1.29 The structures of the $\beta$-nicotinamide adenine dinucleotide redox couple, $\mathrm{NAD}^{+} / \mathrm{NADH}$, and $\beta$-nicotinamide adenine dinucleotide phosphate, NADPH. The two faces of the nicotinamide ring, and thus the hydrogens at the $\mathrm{C} 4$ position in the reduced forms, NADH and NADPH, are not equivalent. In the figure the $\alpha$-face faces out from the page and the $\beta$-face faces into the page.

pattern found around the porphyrin ring (Figure 1.30). Because these substituents are directly attached to the ring, they directly affect the redox potential of the central $\mathrm{Fe}^{3+/ 2+}$ couple. Consequently the redox potentials of different hemes can vary quite widely.

The cytochrome $f$ found in the photosynthetic cytochrome $b f$ complex is a $c$-type cytochrome, but has a very different protein structure; cytochrome $f$ is an elongated protein with a largely $\beta$-sheet secondary structure in contrast to the usual $\alpha$-helical structure found for most $c$-type cytochromes [6].

\subsubsection{Iron-Sulfur Clusters}

Iron-sulfur clusters contain iron atoms bonded to both inorganic sulfur atoms and sulfur atoms on cysteine residues of the associated protein (Figure 1.31). In some $2 \mathrm{Fe} 2 \mathrm{~S}$ clusters, so-called Rieske clusters as found in the cytochrome $b f$ and $\mathrm{CoQH}_{2}$-cyt $c$ reductase complexes, two of the cysteine ligands are replaced by histidine. The iron atoms within the clusters have formal oxidation states of either +2 or +3 , but in actual fact the charge is delocalised between the iron atoms within the cluster [72]. The clusters thus function as multielectron redox centres able to pick up or release electrons one at a time.

\subsubsection{Copper Centres}

Copper occurs as a one-electron centre going between the $\mathrm{Cu}^{+}$and $\mathrm{Cu}^{2+}$ states. In plastocyanin, the copper is coordinated by $\mathrm{N}$ and $\mathrm{S}$ ligands from histidine, cysteine and methionine amino acid residues in an environment which is distorted towards tetrahedral geometry. This helps to stabilise the $\mathrm{Cu}^{+}$state relative to $\mathrm{Cu}^{2+}$ [73], so that the redox potential of $\mathrm{Cu}^{2+/+}$ in plastocyanin in $+370 \mathrm{mV}$ vs NHE, whereas the corresponding value for the aquo copper ion is $+170 \mathrm{mV}$. In cytochrome $c$ oxidase the three $\mathrm{Cu}$ atoms are in different environments. The single $\mathrm{Cu}$ atom $\left(\mathrm{Cu}_{\mathrm{b}}\right)$ is directly associated with the heme group of the cytochrome $a_{3}$ at the site of oxygen reaction, whereas the other two of $\mathrm{Cu}$ atoms (the $\mathrm{Cu}_{\mathrm{a}}$ site) are in distorted tetrahedral coordination, bridged by two cysteine thiolates and coordinated by either histidine and methionine residues or by histidine and glutamate residues [39]. As a result, the two $\mathrm{Cu}_{\mathrm{a}}$ atoms are in different coordination environments and have been suggested to form a mixed valence complex.

\subsection{GOVERNING PRINCIPLES}

Having described the electron transport pathways involved in energy transduction in some detail and looked 


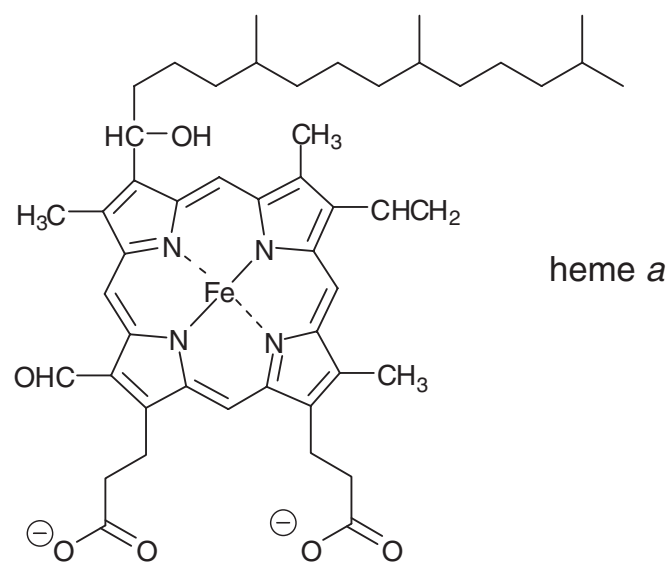

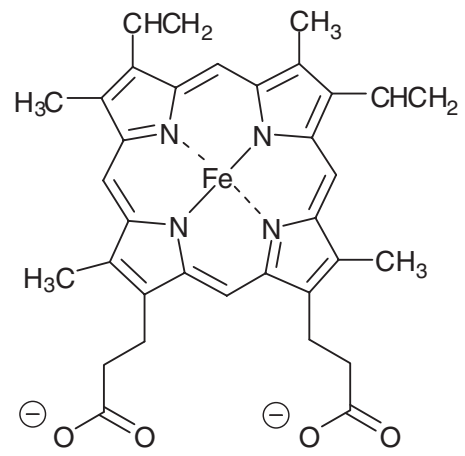

heme $b$

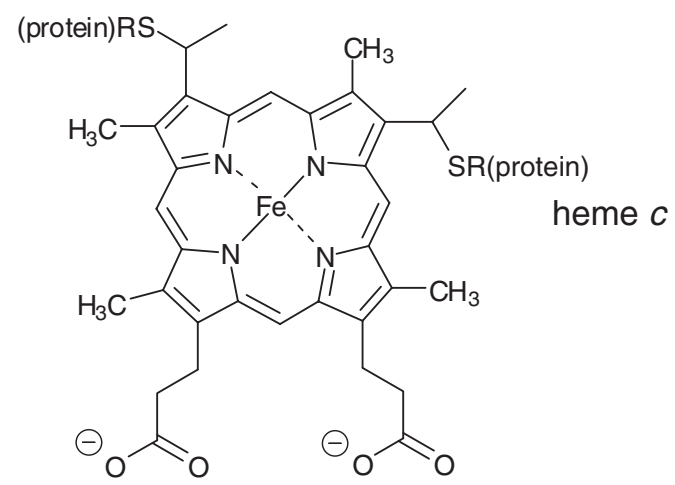

Figure 1.30 The structures of common hemes.

at the different redox centres involved, we are in a position to think about some of the common general guiding principles that determine the efficient operation of these systems. For example, it is clear from our discussion that organisation of the redox species with respect to the lipid membrane is important, and that it is essential to ensure that the electron transfer reactions which occur within the electron transport chains occur between specific partners within the chain. If this breaks down, the organism will either not be able to capture energy efficiently from sunlight or will not be able to utilise the energy from food to make ATP. Thus, compounds which block the photosynthetic electron transport chain or intercept the mitochondrial electron transport chain are highly toxic to living systems. Defects in the efficiency of proton pumping across the mitochondrial membrane are associated with a wide range of human diseases, particularly those affecting the brain and muscle, where large amounts of ATP are used, although single organs or combinations of organs can be affected $[18,19]$.

It is also clear that the properties of the phospholipid membrane, as a barrier to transport of protons between the inside and outside of the structure and as an environment in which to embed the large electron transfer proteins, is crucial in order to establish the proton motive force which ultimately drives synthesis of ATP in the living cell. We have also seen that these processes are achieved with a relatively restricted palette of redox centres and it is therefore of importance to consider the ways in which the properties of these redox centres, in particular their redox potentials, can be tuned within the system to optimise them for their place within the electron transport chain. We also need to consider the factors which control the rates of electron transfer between the different members of the electron transfer chain, both within multicentre redox proteins [74] and between different components. In this section we consider these different general points in turn starting with the membrane itself.

\subsubsection{Spatial Separation}

Phospholipids are amphiphilic molecules with a hydrophilic headgroup and a hydrophobic tail. To make the phospholipid membrane, the individual phospholipid molecules assemble with their headgroups on the outside and the hydrophobic tails on the inside in a bilayer membrane (Figure 1.32). This membrane is about 4 or $5 \mathrm{~nm}$ thick and is essentially impermeable to ions, including protons. The various membrane-bound proteins associated with the phospholipid bilayer make up a significant component of the overall membrane. For example, the inner mitochondrial membrane is typically $24 \%$ lipid and $76 \%$ protein, while the chloroplast membrane is only $25-30 \%$ lipid and $70-75 \%$ protein [75].

The lipid component is made up of a complex mixture of many different lipids that is different for 


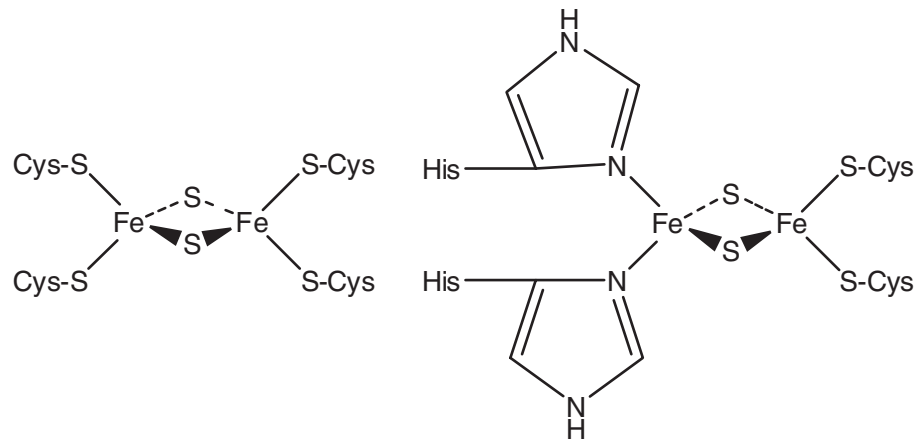

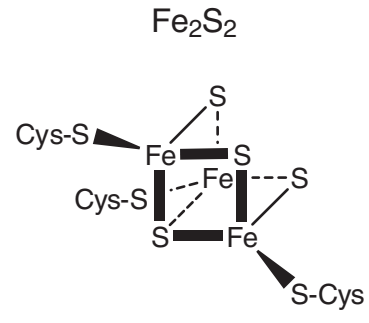

$\mathrm{Fe}_{3} \mathrm{~S}_{4}$

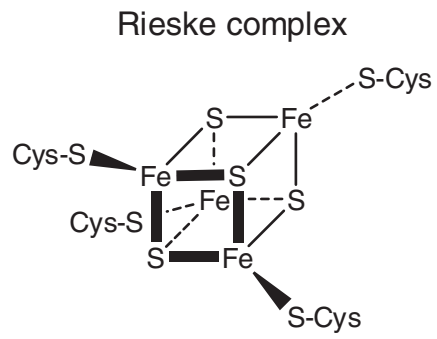

$\mathrm{Fe}_{4} \mathrm{~S}_{4}$

Figure 1.31 The structures of the common iron-sulfur clusters.

the mitochondrial membrane, the chloroplast and other biological membranes, and which is different for the inner and outer layers of the bilayer. This complexity, there are over 1000 different lipids in mammalian cells, indicates that there is some tuning of the properties of the lipid bilayer for different applications [76-78]. Figure 1.33 shows the structures of some common glycerophospholipids, that is phospholipids based on phosphatidic acid (3-sn-phosphatidic acid) esterified with different headgroups.

Galactophospholipids make up as much as $70 \%$ of the lipids in the chloroplast thylakoid membrane. Studies of the phospholipid composition of chloroplasts and mitochondria from avocado and cauliflower showed differences in the precise composition between the species and major differences between the chloroplast and mitochondrion in both cases [76]. Diphosphatidylglycerol (cardiolipin) is highly enriched in the inner mitochondrial membrane and is not generally present in other cellular membranes; phosphatidylethanolamine is relatively more abundant and phosphatidylserine relatively less abundant in mitochondrial inner membranes [77]. The particular composition of the phospholipid bilayer determines its fluidity, which then regulates the properties of proteins embedded within it. It is also important to note that the composition of the lipid layer will not be homogeneous; there is good evidence for a non-uniform distribution of the different phospholipids within the membrane and association between specific proteins and specific phospholipids.

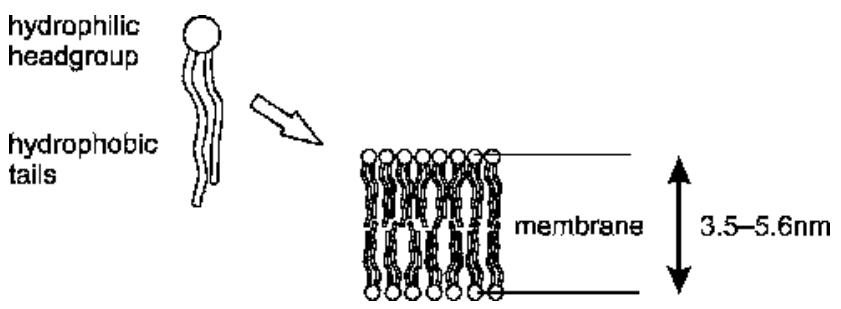

Figure 1.32 A schematic of the phospholipid bilayer membrane. 


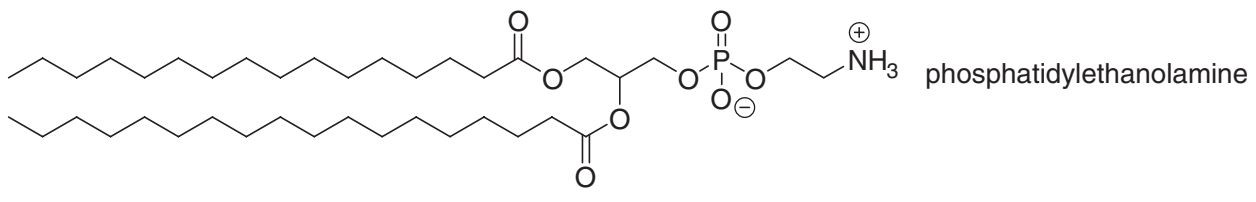

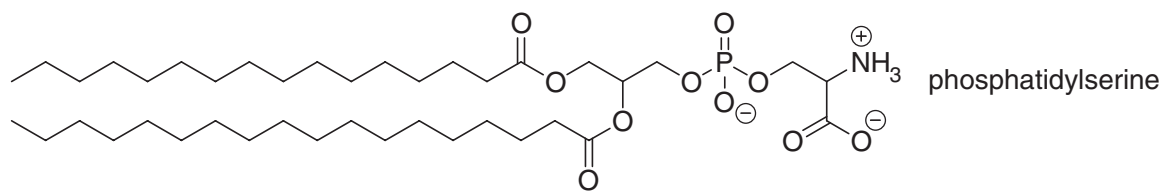<smiles></smiles>

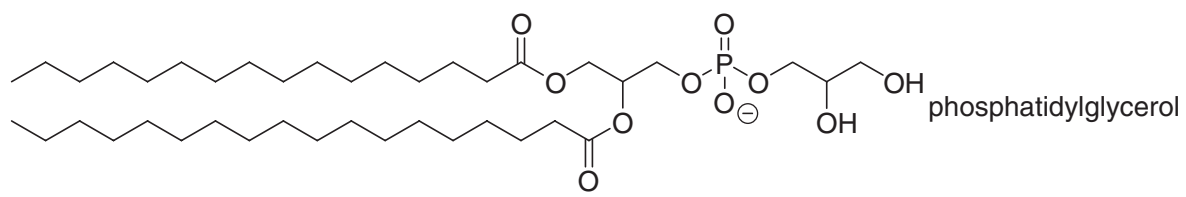<smiles>CCCCCCCCCCCCCCCCCCCCCCCCCCCCCCCCCCCCCCCC(=O)OCC(COP(=O)([O-])CC(O)CP(=O)([O-])OCC(COC(=O)CCCCCCCCCC)OC(=O)CCCCCCCCC)OC(=O)CCCCCCCCCCC</smiles>
diphosphatidylglycerol (cardiolipin)

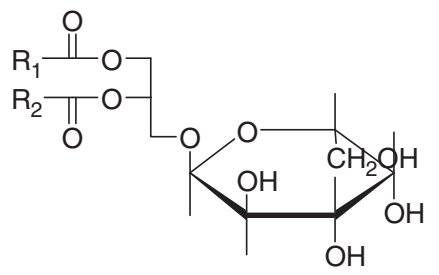

galactolipid

Figure 1.33 The structures of some common phospholipids.

\subsubsection{Energetics: Redox Potentials}

When we look at the energetics of electron transfer along the mitochondrial electron transport chain, from NADH at one terminus to oxygen at the other (Figure 1.34), we see that the redox potentials of the different couples are organised in a steadily increasing sequence. At each step some part of the available free energy is used to drive the kinetics of electron transfer along the chain, while the remainder is used to pump protons across the mitochondrial membrane 


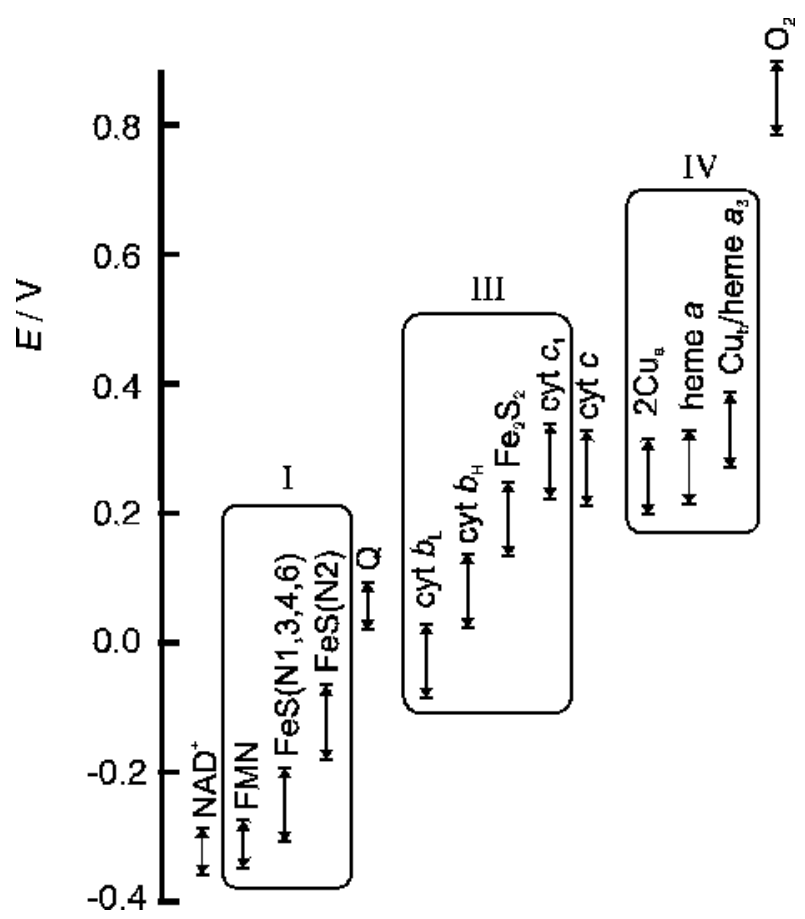

Figure 1.34 The sequence of redox potentials in the mitochondrial electron transport chain from $\mathrm{NAD}^{+}$to $\mathrm{O}_{2}$. The bars represent the range of potentials corresponding to the ratio of oxidised to reduced form from 1:10 to 10:1 (adapted from Smith and Wood [70]).

against the proton motive force (Figure 1.35). The sequence of redox potentials (Figure 1.34) also reveals the kinetic barrier for the reduction of oxygen to water, with by far the greatest drop in redox potential, $\sim 0.2 \mathrm{~V}$, occurring in the final step between $\mathrm{Cu}_{\mathrm{b}}$ /heme $a_{3}$ of cytochrome $c$ oxidase and the water/oxygen couple. This is a situation which is mirrored in current attempts to produce efficient fuel cells, where the slow electrode kinetics of the oxygen reduction reaction at neutral or acidic $\mathrm{pH}$ are a significant limitation on the efficiency of current fuel cells and biofuel cells.

An examination of the sequence of redox potentials for the components of the photosynthetic electron transfer pathway reveals the same story, albeit in this case there are two large endergonic steps corresponding to the adsorption of two photons (Figure 1.36).

This precise tuning of the redox potentials of the different constituents of the mitochondrial and photosynthetic electron transfer chains is achieved by control of the coordination sphere and environment of the different constituent redox centres. Thus, in the case of the heme proteins, the heme centre is bound to the polypeptide by two thioether bonds involving two cysteine residues. The redox potential of the $\mathrm{Fe}^{\mathrm{III}} / \mathrm{Fe}^{\mathrm{II}}$ centre in the heme is altered by the coordination of two axial ligands, either a histidine and a methionine or two histidines above and below the heme plane, to the $\mathrm{Fe}$ centre and by the interaction of the heme with the surrounding polypeptide [79]. If we consider the full range of hemes in biological systems we find that the potentials for the $\mathrm{Fe}(\mathrm{III}) / \mathrm{Fe}(\mathrm{II})$ couple span $0.7 \mathrm{~V}$ from $-0.3 \mathrm{~V}$ in histidine/histidine ligated heme $c$ to $+0.4 \mathrm{~V}$ vs SHE in histidine/methionine ligated heme $c$ [73]. This wide variation of redox potentials allows heme redox centres to fulfil roles at different stages all the way along the redox chain.

In class I cytochromes $c$, where the two axial ligands are a histidine and a methionine, the redox potential of the Fe centre varies from +0.2 to $+0.38 \mathrm{~V}$ vs SHE [80] and this is attributed to the $\pi$ electron withdrawing effect of the sulfur atoms of the thioether linkages and the axially bound methionine, all of which stabilise the $\mathrm{Fe}$ (II) state, and the poor solvent accessibility of the heme within the hydrophobic polypeptide pocket, again favouring the less charged $\mathrm{Fe}$ (II) state over the $\mathrm{Fe}$ (III) state. The final fine tuning of the redox potential is caused by changes in the electrostatic interactions between the charge on the $\mathrm{Fe}$ centre and the charges on polar amino acid residues within, and on the 


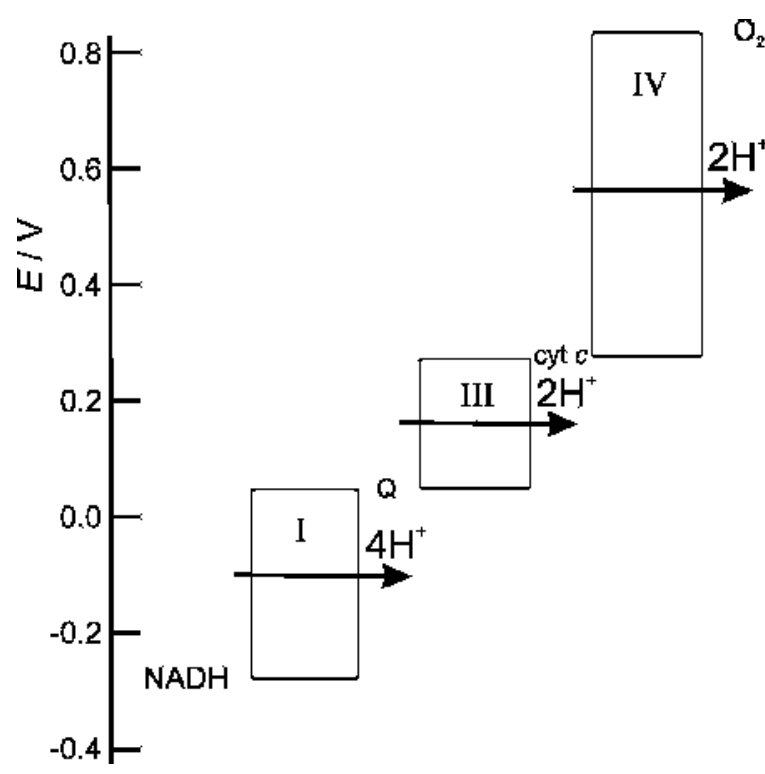

Figure 1.35 The redox potentials for the three main complexes of the mitochondrial electron transport chain showing the number of protons pumped across the membrane at each stage for the transfer of two electrons along the chain. I is the NADH-CoQ reductase complex, II the $\mathrm{CoQH}_{2}-\mathrm{Cyt} c$ reductase complex and IV is the Cyt $c$ oxidase complex; $\mathrm{Q}$ is ubiquinone and cyt $c$ is cytochrome $c$.

surface of, the protein. For example, site directed mutagenesis studies of myoglobin have shown that replacing a valine (an uncharged amino acid residue) which is in van der Waals contact with the heme by glutamate or aspartate (both negatively charged amino acid residues) shifts the potential of the $\mathrm{Fe}(\mathrm{III}) / \mathrm{Fe}$ (II) couple by $-0.2 \mathrm{~V}$. Replacing the same valine by asparagine (which is uncharged) shifts the redox potential by $-0.08 \mathrm{~V}$ [81]. In general, for type I cytochromes $c$, the modification of internal charges causes a 50 to $60 \mathrm{mV}$ shift, whereas modification of surface charges has a smaller effect $(10$ to $30 \mathrm{mV})[79,80]$. Similar effects have been demonstrated for cytochrome $b_{562}$ variants [82].

A similar situation pertains for the flavin two electron, two proton redox couple. The redox potential of free flavin in solution at $\mathrm{pH} 7$ is $-0.21 \mathrm{~V}$ vs SHE [71]. However, the redox potentials of flavin in redox proteins and redox enzymes spans a wide range. In this case, the redox potential of the flavin is modulated by its immediate environment and by the significant difference between the typical dielectric constant for the interior of the protein, $\sim 5$, and the much larger value for water, 78. Stacking interactions with aromatic amino acid residues above and below the flavin ring within the protein, also exert a

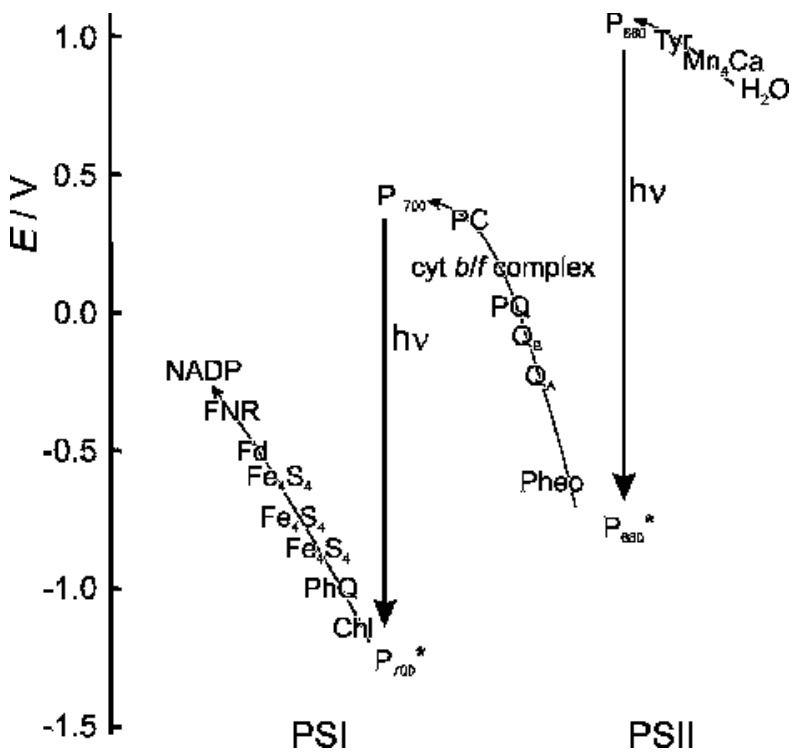

Figure 1.36 The sequence of redox potentials in the photosynthetic electron transport chain (adapted from Blankenship [6]).

significant effect on the redox potential [83-87]. In the case of flavodoxins, these effects lead to a large shift (around $-0.45 \mathrm{~V}$ ) of the flavin potential relative to that in water.

The blue copper proteins are another example where the potentials of the redox centre span a range of values [88], in this case from $0.37 \mathrm{~V}$ vs NHE in $P$. nigra plastocyanin to $0.785 \mathrm{~V}$ vs. NHE in Polyporus versicolor laccase. Again, these differences can be explained by differences in the axial ligands around the $\mathrm{Cu}$ centre and by the degree of hydrophobicity of the polypeptide surrounding the redox centre. It is interesting to note that in the case of the blue copper proteins the coordination geometry about the $\mathrm{Cu}$ centre is virtually identical in the $\mathrm{Cu}(\mathrm{I})$ and $\mathrm{Cu}$ (II) redox states. Consequently there is very little reorganisation accompanying the electron transfer and the reorganisation energy (see below) is low, $E_{\mathrm{R}} \sim 0.6$ to $0.8 \mathrm{eV}$, leading to fast electron transfer kinetics.

\subsubsection{Kinetics: Electron Transfer Rate Constants}

Organising the redox potentials of the individual couples in the electron transport pathways in sequence is only one part of the story. The ordering of the redox potentials controls the thermodynamic driving force for the reaction between each sequential pair of components in the chain, 
but it cannot prevent non-specific electron transfer reactions between disparate components; indeed the thermodynamic driving force for these undesirable reactions may be significantly greater than for the specific, sequential electron transfer. Therefore, in addition to ordering of the redox potentials of the couples, there has to be significant selectivity in the kinetics of the reactions. This is achieved in several ways: spatial separation of components across the membrane, control of the distance for electron transfer, and the use of one- and two- electron couples.

Electron transfer is, at its core, a quantum process (for an in depth discussion of the theory of electron transfer see [89]). The basic model for electron transfer reactions was developed by Marcus, Hush, Levich and Dogonadze in a series of contributions starting in the 1950s [90,91]. The basic versions of the theory are predicated on the separation of fast electronic motion and slow nuclear motion - the Franck-Condon principle. According to this model, electron transfer occurs by tunnelling between reactant and product nuclear vibrational surfaces. The activation energy for the process arises from the reorganisation of the nuclear and solvent coordinates required to bring the reactant system to a configuration in which the electron can transfer adiabatically to the product surface. In the basic treatment of electron transfer kinetics, the reactant and product energy surfaces are treated as parabolic and we have a model, as shown in Figure 1.37. Here

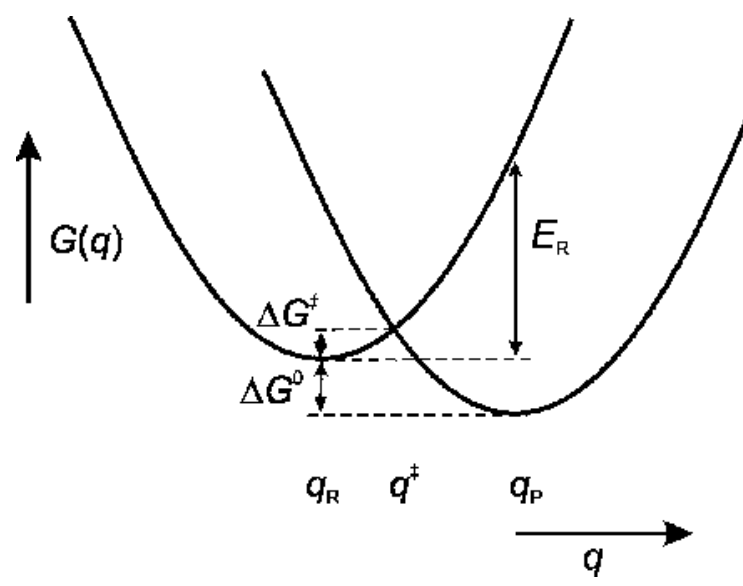

Figure 1.37 Gibbs free energy surface $G(q)$ where $q$ is the reaction coordinate, for an electron transfer reaction showing the reactant and product curves. $\Delta G^{0}$ is the thermodynamic driving force for the reaction, $\Delta G^{\ddagger}$ is the activation free energy for the reaction, $E_{\mathrm{R}}$ the reorganisation energy, $q_{\mathrm{R}}, q^{\ddagger}$ and $q_{\mathrm{P}}$ are the configurations of the reactant, transition state and product, respectively. $q$ represents the reaction coordinate and includes both the inner and outer contributions, where the inner contributions refer to the nuclear rearrangement of the nuclei of the redox centres themselves and the outer contributions refer to the solvent environment around the reactant centres. $\Delta G^{0}$ is the thermodynamic driving force and $\Delta G^{\ddagger}$ is the activation energy for the reaction. The rate constant for electron transfer between the donor and acceptor

$$
\mathrm{D}+\mathrm{A} \rightarrow \mathrm{D}^{+}+\mathrm{A}^{-}
$$

is given by

$$
k_{\mathrm{DA}}=\kappa_{\mathrm{el}} \frac{\omega_{\mathrm{eff}}}{2 \pi} \exp \left(\frac{-\Delta G^{\ddagger}}{R T}\right)
$$

In this equation, $\omega_{\text {eff }}$ is the effective frequency of the nuclear motions which brings the system to the transition state configuration $q^{\ddagger}$, and $\kappa_{\mathrm{el}}$ is the electron transfer probability at the nuclear configuration of the transition state. Assuming that the reactant and product energy surfaces are parabolic and of the same shape the free energy of activation can be written

$$
\Delta G^{\ddagger}=\frac{\left(E_{R}-\Delta G^{0}\right)^{2}}{4 E_{R}}
$$

Equation (1.25) makes explicit the relationship between the activation energy and the thermodynamic driving force for the reaction, and predicts a quadratic dependence of $\ln \left(k_{\mathrm{DA}}\right)$ on $\Delta G^{0}$. This prediction has been verified for a number of systems including studies of electron transfer in ruthenium modified myoglobin [92], in which ruthenium redox centres were attached to a specific histidine residue on the surface of the protein and the rate of electron transfer between different ruthenium amine complexes and the active site were measured. In these experiments the thermodynamic driving force for the reaction was changed by changing the metal in the porphyrin at the active site (native $\mathrm{Fe}, \mathrm{Cd}, \mathrm{Mg}, \mathrm{Zn}, \mathrm{Pd}$ and proton) and by changing the ligands on the ruthenium attached to the peripheral histidine. In this way, the driving force for the electron transfer was varied from 0.39 to $1.17 \mathrm{eV}$ giving around a 1000-fold change in the rate of intramolecular electron transfer. For the photosynthetic reaction centre, electron transfer has been shown to follow a quantum corrected Marcus expression [93].

The quantity $E_{\mathrm{R}}$ in Equation (1.25) is the reorganisation energy. It corresponds to the free energy required to reor- 
ganise the nuclear coordinates for the reactant from those corresponding to equilibrium for the reactants $q_{\mathrm{R}}$, to those corresponding to the equilibrium organisation for the products, $q_{\mathrm{P}}$, but without transfer of the electron (Figure 1.37). The reorganisation energy, $E_{\mathrm{R}}$, includes both the inner and outer sphere contributions to the reorganisation process. From Figure 1.37 it is clear that small values of $E_{R}$, corresponding to similar structures for reactants and products, and/or broad parabolic free energy surfaces, corresponding to an easy reorganisation process, will give larger values of the electron transfer rate constant, $k_{\mathrm{DA}}$. In general, even for fast electron transfer reactions, $E_{\mathrm{R}}$ is a large quantity many times bigger that $k T$. For biological systems, the protein surrounding the redox centre plays an important role in reducing the reorganisation energy and, as a consequence, speeding up electron transfer reactions [94]. A large part of this reduction in $E_{\mathrm{R}}$ is caused by the exclusion of water. Bulk water has a high dielectric constant $(\varepsilon=78)$ and therefore interacts strongly with the charge, and the change in charge that accompanies electron transfer, at the redox centre. In contrast, the dielectric constant of the protein is lower (around five) and the interactions with the redox centre consequently smaller. Added to this, the constrained structure of the protein around the redox centre reduces the inner sphere contribution to $E_{\mathrm{R}}$. For example, the reorganisation energies for self-exchange in redox proteins are typically of the order of 0.6 to $0.8 \mathrm{eV}$ [94], whereas the typical values for simple complex ions in aqueous solution are significantly larger (around $2 \mathrm{eV}$ ).

Although the reorganisation process is important in determining the kinetics of electron transfer between donor and acceptor, in order to determine the origin of the selectivity in the kinetics of electron transfer between specific partners in the biological electron transfer pathways, we must turn our attention to the pre-exponential term $\kappa_{\mathrm{el}}$ in Equation (1.24). According to the semi-classical model $\kappa_{\mathrm{el}}$ is given by

$$
\kappa_{\mathrm{el}}=\sqrt{\frac{\pi}{\hbar^{2} E_{\mathrm{R}} R T}} H_{\mathrm{DA}}^{2}
$$

where $H_{\mathrm{DA}}^{2}$ is the electronic coupling matrix element and describes the strength of coupling between the reactant and product states at the nuclear configuration of the transition state. If we assume that the electron transfer occurs by tunnelling through a square, uniform barrier using the Hopfield model, then

$$
H_{\mathrm{DA}}(r)=H_{\mathrm{DA}}\left(r_{0}\right) \exp \left(\frac{-\beta\left(r-r_{0}\right)}{2}\right)
$$

where $r_{0}$ is the van der Waals contact distance for the donor and acceptor and $\beta$ describes the exponential attenuation of the overlap with distance between the donor and acceptor. The simple exponential dependence of the rate of electron transfer with distance predicted by Equations (1.24) to (1.27) can be understood in terms of the drop off of the electronic wavefunctions of the donor HOMO and acceptor LUMO orbitals with distance. In general, these will decrease exponentially at larger distances from the redox centre; the overlap of these two exponentially decaying wavefunctions, then, itself yields an exponential dependence on the separation of donor and acceptor. There is some debate as to whether the distance between donor and acceptor should be measured between the metal centres in the redox groups in species such as hemes, or between the edges of the ligands [94].

The parameter $\beta$ in Equation (1.27) depends on the nature of the intervening medium through which the electron tunnels. For an electron tunnelling through a vacuum, $\beta$ is generally taken to be between 30 and $50 \mathrm{~nm}^{-1}$ [94]. However, when the electron tunnels through an intervening medium between the donor and acceptor, the value of $\beta$ is reduced, because the height of the tunnel barrier is reduced; the electron is able to travel further. For protein a value of $\beta$ of $14 \mathrm{~nm}^{-1}$ has been suggested based on a range of experimental measurement [93]. This means that for every $0.17 \mathrm{~nm}$ increase in the distance between the donor and acceptor, the rate of electron transfer will decrease by a factor of 10 .

The topic of long range electron transfer remains an area of significant interest, not only within bioelectrochemistry, but also in the field of molecular electronics and nanotechnology $[95,96]$ and there have been many elegant studies on model systems. One of these that is particularly relevant to bioelectrochemistry is the work of Isied et al. [97] who studied the distance dependence of electron transfer between two metal complexes separated by an oligoproline bridge (Figure 1.38). Oligoproline bridges were selected because their rigidity allows the spacing between donor and acceptor to be well defined; the molecule cannot fold up to bring the donor and acceptor ends close to each other. They found an exponential decrease in the rate of electron transfer with increasing distance up to three or four proline molecules in the bridge (corresponding to a donor/acceptor spacing of $\sim 2 \mathrm{~nm}$ ), and beyond that a levelling off of the electron transfer rate. They suggest several possible explanations for this change in terms of different pathways for electron transfer, including the possibility of a change from through-space to through-bond electron transfer. 
0

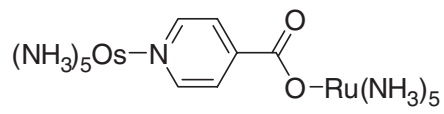

1<smiles></smiles>

2<smiles></smiles>

3<smiles>CCCCCN1CCCC(C(=O)N2CCCC2C(=O)N2CCCC2C(=O)OC=N)C1=O</smiles>

4

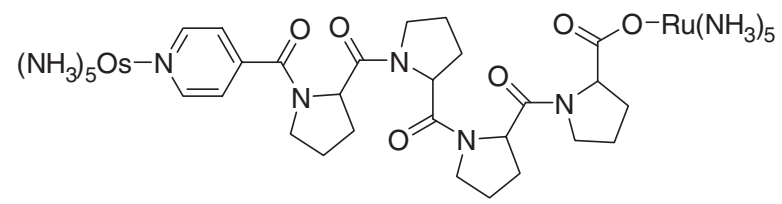

Figure 1.38 The structures of a set of oligoproline bridged ruthenium-osmium donor-acceptor complexes (based on Isied et al. [97]).

The study of electron transfer in proteins has been significantly advanced over the last 15 years by our increasing knowledge of the precise three-dimensional structures of various redox proteins and by the application of protein engineering to allow the systematic investigation of the effects of the mutation of individual amino acids on the rates of electron transfer. The simple Hopfield model described above treats the protein between the donor and acceptor sites as a homogeneous, featureless medium. In practice, the donor and acceptor are separated by the peptide, which comprises various amino acid residues in a particular sequence and orientation. This has led to a vigorous debate as to whether there exist specific electron transfer pathways within proteins [94,98102], or whether the process can be described purely in terms of a distance dependence [103,104]. In the tunnelling pathway model proposed by Beratan et al. $[98,99,105]$, the pathway between the donor and acceptor is divided into a number of segments corresponding to covalently bonded parts, hydrogen bonded parts, and through-space parts where there is van der Waals contact. The overall decay of the tunnelling interaction is then treated as the product of the decay across each block. There is then an approximately exponential decay in coupling with the number of blocks in the tunnelling pathway, so that relatively few pathways make an important contribution to the coupling between donor and acceptor within the model. These contributing pathways are identified using a structure searching algorithm. Support for this model comes from studies of electron transfer in ruthenium modified cytochromes $c$ [100], where better agreement is found between the logarithm of the electron transfer rate and the calculated path length rather than the physical distance.

According to the pathway model, the coupling through a $\beta$ peptide strand should be greater than that through an $\alpha$ helix, because in the $\alpha$ helix the distance between the two ends increases much more slowly, and non-linearly, with the helix length, as compared to the case for the more linear $\beta$ strand $[102,106]$ (Figure 1.39). Using site directed mutagenesis, Langen et al. attached ruthenium 


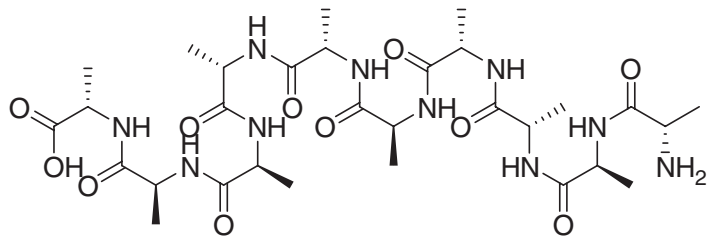

alpha helix<smiles>CC(NC(=O)C(C)NC(=O)[C@H](C)NC(=O)[C@H](C)NC(=O)[C@H](C)NC(=O)[C@H](C)NC(=O)[C@H](C)NC(=O)[C@H](C)NC(=O)[C@H](C)NC(=O)[C@H](C)NC(=O)[C@H](C)N)C(=O)O</smiles>

Figure 1.39 The structures for the $\alpha$ helix and $\beta$ strand showing the relative lengths of the two for a decapeptide.

complexes to histidine residues introduced at different places along the $\beta$ barrel of the azurin from Pseudomonas aeruginosa, and measured the rate of electron transfer between the ruthenium and the $\mathrm{Cu}(\mathrm{I})$ [102]. They found an exponential dependence of the rate of electron transfer with distance, with a decay constant of $11.0 \mathrm{~nm}^{-1}$, close to that predicted for coupling along a $\beta$ strand by the pathway model.

The experimental studies described above refer to intramolecular electron transfer in proteins. In the biological system, intermolecular electron transfer also plays a significant role. Here again we can expect the distance dependence to play an important role. In the case of intermolecular electron transfer, particularly when one or both of the reactants is large, the orientation of the two molecules will have a significant effect and allows selectivity to be introduced into the process - electron transfer will be fast between those components which bind together in the correct orientation to bring the redox centres close together. However, from the point of view of experimental studies, the uncertainty in the precise geometry of the complex formed between the reactants makes it much harder to study the fine details of electron transfer in the reaction complex formed by two large proteins. Recent interest has focused on the role of water molecules between the two reactants and the existence of electron tunnelling pathways through the structured water trapped between the proteins [107].

\subsubsection{Size of Proteins}

A consequence of the need for selectivity in electron transfer reactions in electron transport chains, and therefore the concomitant need to control the environment around the redox centre to tune its potential and the distance dependence of the rate of electron transfer, is that the redox proteins involved have to be reasonably large molecules. For example, if we consider the multicentre transmembrane proteins, such as the NADH-CoQ reductase complex or photosystem II, it is clear that they must be large enough to span the phospholipid membrane and that, in addition, they need to be larger enough to separate out the different redox centres within the protein in order to control the rates of electron transfer between the different centres. In essence, a separation of more that about $1.4 \mathrm{~nm}$ is required in order to kinetically limit electron transfer between centres [104].

The possible factors which determine the size of soluble proteins have been described by Goodsell and Olson [108]. They highlight three effects. First, the requirement that the length of the poly(peptide) chain is long enough to enforce the overall shape of the protein [109]. This is supported by the observation that many smaller proteins contain disulfide linkages or rigid metal clusters which enhance the stability of the folded protein. Second, the suggestion, originally attributed to Pauling [108], that in order to control association between proteins it is necessary to decrease the ratio of surface to volume and to ensure that the surface area is large enough to allow patterning of the surface, so that there can be specific interactions between reaction partners [109]. This effect is seen, for example, in the interaction of plastocyanin with cytochrome $f$ in the chloroplast or the interaction between cytochrome $c$ and the cytochrome $b c_{1}$ complex in the mitochondrion. Finally, Goodsell and Olson suggest that, for some reactions, surface diffusion, where the reactant diffuses across the protein surface to the active site, is an important factor [110]. 


\subsubsection{One-Electron and Two-Electron Couples}

Looking back at the mitochondrial or photosynthetic electron transport chains (Figures 1.8 and 1.18), it is clear that a final factor which provides control and selectivity over electron transfer is the division between one-electron redox couples, such as hemes or $\mathrm{Cu}$ centres, and two-electron redox couples such as NADH. For the $\mathrm{NAD}(\mathrm{P}) / \mathrm{NAD}(\mathrm{P}) \mathrm{H}$ couple, the one-electron oxidation or reduction intermediate is not readily accessible and redox reactions in biological systems proceed by a formal hydride transfer mechanism. As a consequence, the rates of reaction between $\mathrm{NAD}(\mathrm{P}) \mathrm{H}$ and one-electron couples in the electron transfer chain, although thermodynamically favourable, are slow. This, together with the fact that oxygen has a triplet ground state, also accounts for the slow reaction of $\mathrm{NAD}(\mathrm{P}) \mathrm{H}$ with oxygen, another factor which is vital for the operation of both mitochondrial and photosynthetic electron transport chains. Thus, the NAD (P)H couple is able to exchange electron pairs with redox couples such as succinate/fumarate or lactate/pyruvate, but not to short circuit electron transfer directly to oxygen or other components of the electron transport chain.

Clearly the two-electron redox world of $\mathrm{NAD}(\mathrm{P}) \mathrm{H}$ and the one-electron redox world of the hemes, iron-sulfur clusters and $\mathrm{Cu}$ proteins need to be linked together and this is achieved by the flavin redox couple which is equally at home as a two-electron redox couple reacting with $\mathrm{NAD}(\mathrm{P}) \mathrm{H}$ or as a redox couple reacting in two oneelectron steps via a thermodynamically and kinetically viable semiquinone radical intermediate [71]. Examples of this linkage can be found in the crystallographic studies of ferredoxin-NADP ${ }^{+}$reductase $[66,111,112]$ and glutathione reductase $[113,114]$. These show that the hydride transfer occurs through a stacked flavin-NADP ${ }^{+}$complex that confers the correct geometry for the hydride transfer (Figure 1.40).

\subsection{ATP SYNTHASE}

It is appropriate that we conclude this chapter with a discussion of ATP synthase. The ATP synthase enzymes from different organisms, including those from mitochondria, chloroplasts, fungi and bacteria, show a very high degree of conservation in structure and function. The enzyme sits in the membrane and utilises the proton motive force generated by the different electron transport chains described above to carry out the synthesis of ATP from ADP and inorganic phosphate.

ATP synthase [5,115-118] (Figure 1.41), is a multisubunit enzyme made up of an $\mathrm{F}_{0}$ membrane bound portion

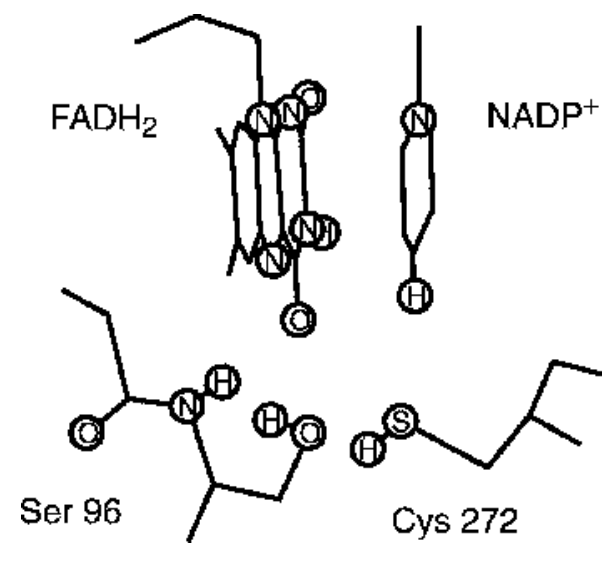

Figure 1.40 The stacked flavin $\mathrm{NADP}^{+}$structure required for hydride transfer based on the structure in the binding site of ferredoxin reductase (based on Karplus and Bruns [111]). Ser 92 and Cys 272 are residues of the ferredoxin involved in binding the flavin and $\mathrm{NADP}^{+}$. The aromatic rings of the flavin and $\mathrm{NADP}^{+}$ are held face to face $0.33 \mathrm{~nm}$ apart with the nicotinamide $\mathrm{C} 4$ opposite the flavin N5 atom.

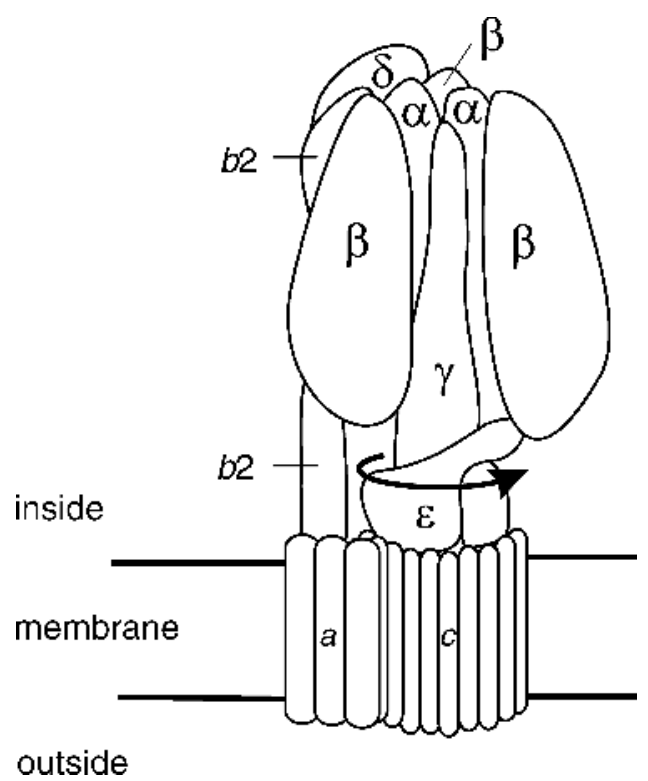

Figure 1.41 The general structure of $\mathrm{F}_{0} \mathrm{~F}_{1}$ ATP synthase from Escherichia coli (adapted from Capaldi and Aggeler [5]). The $a, b$, three $\alpha$, three $\beta$, and $\delta$ sub-units make up the stator and the nine to twelve $c, \gamma$ and $\varepsilon$ sub-units make up the rotator. 
and a soluble $F_{1}$ portion which can be dissociated by treatment in low ionic strength buffer. This soluble $F_{1}$ portion remains catalytically active after dissociation. The $\mathrm{F}_{0}$, membrane bound, portion of ATP synthase from Escherichia coli is made up of three sub-units, $a, b$ and $c$, in the ratio $1: 2: 10-14$. The $\mathrm{F}_{0}$ portion provides a specific proton conduction channel between the $c$ sub-unit ring and the $a$ unit. The catalytic sites for ATP synthesis are located in the $F_{1}$ portion of the enzyme, which comprises three subunits, $\alpha, \beta$ and $\gamma$, in the ratio $3: 3: 1$. The $\alpha$ and $\beta$ sub-units form a hexagon with the three catalytic sites located at the interface between the units. The helical region of the $\gamma$ subunit passes through the core of the $\alpha_{3} \beta_{3}$ hexagon. The other end of the $\gamma$ sub-unit and the $\varepsilon$ sub-unit are securely attached to the $c$ ring. During the catalytic cycle, the passage of protons through the $\mathrm{F}_{0}$ potion of the enzyme drives the $c$ ring around and thus causes the helical portion of the $\gamma$ sub-unit to rotate within the $\alpha_{3} \beta_{3}$ hexagon, which is itself held stationary by viscous drag from the two $b$ sub-units and the $\delta$ sub-unit. In the catalytic cycle, the three catalytic sites pass sequentially through three different conformations substrate binding, formation of tightly bound ATP, release of ATP - brought about by the rotation of the $\gamma$ sub-unit (Figure 1.42). Each $120^{\circ}$ rotation leads to the synthesis, or
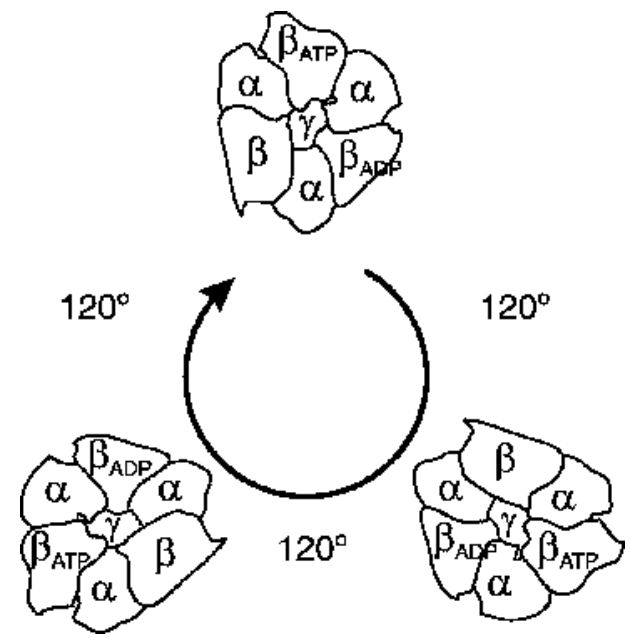

Figure 1.42 The proposed mechanism for ATP synthesis (based on Capaldi and Aggeler [5] and Yashuda et al. [126]). The three catalytic sites (each $\alpha \beta$ sub-unit pair) are in different conformations; one is open $(\beta)$ and ready to bind ADP and inorganic phosphate or ATP, one is partly open $\left(\beta_{\mathrm{ADP}}\right)$ and contains ADP and inorganic phosphate, the third is closed $\left(\beta_{\mathrm{ATP}}\right)$ and contains ATP. Rotation of the central $\gamma$ sub-unit drives the catalytic sites sequentially through the sequence leading to the endergonic conversion of ADP and inorganic phosphate to ATP. hydrolysis, of one molecule of ATP. Thus in ATP synthase, mechanical rotation is the mechanism by which the free energy of the proton motive fore is converted into the chemical potential of ATP.

Evidence for this mechanism comes from a variety of sources, including radio labelling and specific cross-linking studies $[119,120]$, fluorescent labelling studies [121], by nmr [122], by cross-linking [123] and through direct observation of single molecules using epi-fluorescent microscopy [124-126]. In these experiments, Yasuda et al. immobilised $\mathrm{F}_{1}$-ATPase from $E$. coli onto Ni-NTA modified surfaces by histidine tagging of the $\alpha$ and $\beta$ subunits. The rotation of the $\gamma$ sub-unit was then observed by attaching a biotinylated, fluorescently labelled actin filament, around $5 \mathrm{~nm}$ in length, through strepavidin to the $\gamma$ sub-unit. When $2 \mathrm{mM}$ ATP was added to the solution, they observed the continuous rotation of the actin filament in an anti-clockwise direction when viewed from above (corresponding to the membrane side) with a rotational torque of $\sim 40 \mathrm{pN} \mathrm{nm}^{-1}$. In subsequent experiments [125], they showed that at low ATP concentration, $<\mu \mathrm{M}$, the $\gamma$ subunit rotates in a series of discrete $120^{\circ}$ steps with an average mechanical work of $90 \mathrm{pN} \mathrm{nm}$, corresponding to close to $100 \%$ efficiency for ATP hydrolysis. Then, using high speed imaging [126], they were able to resolve the $120^{\circ}$ rotation into $90^{\circ}$ and $30^{\circ}$ sub-steps, each lasting a fraction of a millisecond. The $90^{\circ}$ sub-step is driven by ATP binding and the $30^{\circ}$ sub-step is postulated to correspond to product release. More recently, using FRET measurements, Diez et al. [127] have shown that the $\gamma$ sub-unit rotates in the opposite direction during ATP synthesis, as expected. In addition, a further demonstration of the chemomechanical coupling has been provided by Itoh et al. [128] using $\mathrm{F}_{1}$-ATPase units immobilised on a surface through histidine tagging of the $\alpha$ and $\beta$ sub-units and with the $\gamma$ sub-unit modified with actin fibres terminated with a magnetic bead. By using an external magnetic field they were able to drive the rotation of the $\gamma$ sub-unit and thus drive ATP synthesis. Despite the significant progress made in understanding the mechanism of ATP synthase a number of questions remain. For example, it is unclear how the transport of the three or four protons through the $c$ sub-units of $\mathrm{F}_{0}$, and the corresponding small rotations of the $c$ sub-unit ring, couple to the $120^{\circ}$ rotations of the $\gamma$ sub-unit [5].

The details of the function of ATP synthase are a fascinating story, which has unfolded over the last 12 years following the determination of the crystal structure of the $F_{1}$ portion of the enzyme [129], through ingenious labelling and modification experiments, and most recently through X-ray structural studies of the membrane bound $F_{0}$ portion [130-132]. The mode of chemomechanical 
coupling of the proton motive force to endergonic chemical reaction is a fascinating example and a future challenge to bioelectrochemists.

\subsection{CONCLUSION}

In this chapter the emphasis has been on the electron transfer steps in the mitochondrial and photosynthetic electron transfer chains. As we have seen, our understanding of these processes and the underlying physical principles is enormously enhanced and informed by the high quality structural information available from high resolution X-ray crystallographic studies of the large membrane bound proteins involved in these processes. It is amazing to realise that it is only really within the last 11 years, starting with the crystal structure determination of cytochrome $c$ oxidase in 1995 that these structures have been elucidated (the single exception to this is the bacterial photosynthetic reaction centre which was first determined in 1988). Clearly, there are still many questions of detail to answer. Equally, it is also clear that there are many important messages and challenges for bioelectrochemists to be found in the way the electron transfer chains are so exquisitely organised and in the way they drive the endergonic synthesis of ATP.

\section{REFERENCES}

1. A. J. Bard, Integrated Chemical Systems. A Chemical Approach to Nanotechnology. John Wiley, New York, 1994.

2. H. Lodish, A. Berk, P. Matsudaira, C. A. Kaiser, M. Krieger, M. P. Scott, S. L. Zipursky and J. Darnell, Mol. Cell Biol. 5th edn., W. H. Freeman, New York, 2003.

3. P. Mitchell, Coupling of phosphorylation to electron and hydrogen transfer by a chemi-osmotic type of mechanism, Nature, 191, 144-148 (1961).

4. P. Mitchell, Keilin's respiratory chain concept and its chemiosmotic consequences, Science, 206, 1148-1159 (1979).

5. R. A. Capaldi, R. and Aggeler, Mechanism of the $\mathrm{F}_{1} \mathrm{~F}_{0}$-type ATP synthase, a biological rotary motor, Trends Biochem. Sci., 27, 154-160 (2002).

6. R. E. Blankenship, Molecular Mechanisms of Photosynthesis. Blackwell Science, Oxford, 2002.

7. D. C. Wallace, Mitochondrial diseases in man and mouse, Science, 283, 1482-1488 (1999).

8. P. Rich, The cost of living, Nature, 421, 583 (2003).

9. T. G. Frey and C. A. Mannella, The internal structure of mitochondria, Trends Biochem. Sci., 25, 319-324 (2000).

10. M. Saraste, Oxidative phosphorylation at the fin de siècle, Science, 283, 1488-1493 (1999).

11. B. E. Schultz and S. I. Chan, Structures and proton-pumping strategies of mitochondrial respiratory enzymes, Ann. Rev. Biophys. Biomol. Struct., 30, 25-65 (2001).
12. V. Guénebaut, R. Vincentelli, D. Mills, H. Weiss and K. Leonard, Three-dimensional structure of NADH-dehydrogenase from Neurospora crassa by electron microscopy and conical tilt reconstruction, J. Mol. Biol., 265, 409-418 (1997).

13. N. Grigorieff, Structure of the respiratory NADH:ubiquinone oxidoreductase (complex I), Curr. Op. Struct. Biol., 9, 476-483 (1999).

14. G. Hofhaus, H. Weiss and K. Leonard, Electron microscopic analysis of peripheral and membrane parts of mitochondrial NADH dehydrogenase (complex I), J. Mol. Biol., 221, 1027-1043 (1991).

15. T. Friedrich, U. Weidner, U. Nehls, W. Fecke, R. Schneider and $\mathrm{H}$. Weiss, Attempts to define distinct parts of NADH: ubiquinone oxidoreductase (complex I), J. Bioenerg. Biomembr., 25, 331-337 (1993).

16. P. Hinchliffe and L. A. Sazanov, Organization of iron-sulfur clusters in respiratory complex I, Science, 309, 771-774 (2005).

17. L. A. Sazanova and P. Hinchliffe, Structure of the hydrophilic domain of respiratory Complex I from Thermus thermophilus, Science, 311, 1430-1436 (2006).

18. T. Yagi, The bacterial energy-transducing NADH-quinone oxidoreductase, Biochim. Biophys. Acta, 1141, 1-17 (1993).

19. H. Weiss, T. Friedrich, H. G. and D. Price, The respiratorychain NADH dehydrogenase (complex I) of mitochondria, Eur. J. Biochem., 197, 563-576 (1991).

20. T. Ohnishi, NADH-quinone oxidoreductase, the most complex complex, J. Bioenerg. Biomembr., 25, 325-329 (1993).

21. U. Brandt, Proton-translocation by membrane-bound NADH: ubiquinone-oxidoreductase (complex I) through redox-gated ligand conduction, Biochim. Biophys. Acta, 1318, 79-81 (1997)

22. C. R. D. Lancaster, A. Kröger, M. Auer and H. Michel, Structure of fumarate reductase from Wolinella succinogenes at $2.2 \AA$ resolution, Nature, 402, 377-385 (1999).

23. C. Hägerhäll and L. Hederstedt, A structural model for the membrane-integral domain of succinate:quinone oxidoreductase, FEBS Lett., 389, 25-31 (1996).

24. C. Hägerhäll, Succinate: quinone oxidoreductases. Variations on a conserved theme, Biochim. Biophys. Acta, 1320, 107-141 (1997).

25. T. M. Iverson, C. Luna-Chavez, G. Cecchini and D. C. Rees, Structure of the Escherichia coli fumerate reductase respiratory complex, Science, 284, 1961 (1999).

26. B. L. Trumpower, The protonmotive Q cycle, J. Biol. Chem., 265, 11409-11412 (1990).

27. E. Darrouzet, C. C. Moser, P. L. Dutton and F. Daldal, Large scale domain movement in cytochrome $b c_{1}$ : a new device for electron transfer in proteins, Trends Biochem. Sci., 26, 445-451 (2001).

28. Z. Zhang, L. Huang, V. M. Shulmeister, Y.-I. Chi, K. K. Kim, L.-W. Hung, A. R. Crofts, E. A. Berry and S.-H. Kim, Electron transfer by domain movement in cytochrome $b c_{1}$, Nature, 392, 677-684 (1998).

29. A. Osyczka, C. C. Moser, F. Daidal and P. L. Dutton, Reversible redox energy coupling in electron transfer chains, Nature, 427, 607-612 (2004). 
30. A. Osyczka, C. C. Moser and P. L. Dutton, Fixing the Qcycle, Trends Biochem. Sci., 30, 176-182 (2005).

31. D. Xia, C.-A. Yu, H. Kim, J.-Z. Xia, A. M. Kachurin, L. Zhang, L. Yu and J. Deisenhofer, Crystal structure of the cytochrome $b c_{1}$ complex from bovine heart mitochondria, Science, 277, 60-66 (1997).

32. M. Saraste, Structural features of cytochrome-oxidase, Quart. Rev. Biophys., 23, 331-366 (1990).

33. M. W. Calhoun, J. W. Thomas and R. B. Gennis, The cytochrome oxidase superfamily of redox-driven proton pumps, Trends Biochem. Sci., 19, 325-330 (1994).

34. G. T. Babcock and M. Wilkstöm, Oxygen activation and the conservation of energy in cell respiration, Nature, 356, 301-309 (1992).

35. H. Michel, J. Behr, A. Harrenga and A. Kannt, Cytochrome $c$ oxidase: structure and spectroscopy, Ann. Rev. Biophys. Biomol. Struct., 27, 329-356 (1998).

36. D. Zaslavsky and R. B. Gennis, Proton pumping by cytochome oxidase: progress, problems and postulates, Biochim. Biophys. Acta, 1458, 164-179 (2000).

37. R. J. P. Williams, Purpose of proton pathways, Nature, 376, 643 (1995).

38. T. Tsukihara, H. Aoyama, E. Yamashita, T. Tomizaki, H. Yamaguchi, K. Shinzawa-Itoh, R. Nakashima, R. Yaono and S. Yoshikawa, The whole structure of the 13-subunit oxidized cytochrome $c$ oxidase at $2.8 \AA$ A, Science, 272, 1136-1144 (1996).

39. S. Iwata, C. Ostermeier, B. Ludwig and H. Michel, Structure at $2.8 \AA$ resolution of cytochrome $c$ oxidase from Paracoccus denitrificans, Nature, 376, 660-669 (1995).

40. K. Faxén, G. Gilderson, P. Ädelroth and P. Brzezinski, A mechanistic principle for proton pumping by cytochrome $c$ oxidase, Nature, 437, 286-289 (2005).

41. M. Wikström, Proton translocation by cytochrome $c$ oxidase: a rejoinder to recent criticism, Biochem., 39, 3515-3519 (2000).

42. Y. Anraku, Bacterial electron transport chains, Ann. Rev. Biochem., 57, 101-132 (1988).

43. S. J. Ferguson, Energy transduction processes: from respiration to photosynthesis in The Desk Encyclopedia of Microbiology, M. Schaechter (ed.), Elsevier, 2003, pp. 392-400.

44. M. W. Gray, G. Burger and B. F. Lang, Mitochondrial evolution, Science, 283, 1476-1481 (1999).

45. T. Unemoto and M. Hayashi, $\mathrm{Na}^{+}$-translocating NADHquinone reductase of marine and halophilic bacteria, J. Mol. Biol., 25, 385-391 (1993).

46. M. G. Bertero, R. A. Rothery, M. Palak, C. Hou, D. Lim, F. Blasco, J. H. Weiner and N. C. J. Strynadka, Insights into the respiratory electron transfer pathway from the structure of nitrate reductase A, Nature Struct. Biol., 10, 681-687 (2003).

47. O. Dym, E. A. Pratt, C. Ho and D. Eisenberg, The crystal structure of D-lactate dehydrogenase, a peripheral membrane respiratory enzyme, Biochem., 97, 9413-9418 (2000).
48. J. Whitmarsh, Electron transport and energy transduction in Photosynthesis: A Comprehensive Treatise, A. S. Raghavendra (ed.), Cambridge University Press, Cambridge, 1997, Chapter 7.

49. J. F. Allen, Photosynthesis of ATP-electrons, proton pumps, rotors, and poise, Cell, 110, 273-276 (2002).

50. J. Barber, The structure of photosystem I, Nature Struct. Biol., 8, 577-579 (2001).

51. J. P. Dekker and E. J. Boekema, Supramolecular organization of thylakoid membrane proteins in green plants, Biochim, Biophys. Acta, 1706, 12-39 (2005).

52. B. Hankamer, J. Barber and E. J. Boekema, Structure and membrane organization of photsystem II in green plants, Ann. Rev. Plant Physiol. Plant Mol. Biol., 48, 641-671 (1997).

53. J. Barber and W. Kühlbrandt, Photosystem II, Curr. Op. Struct. Biol., 9, 469-475 (1999).

54. Z. Liu, H. Yan, K. Wang, T. Kuang, J. Zhang, L. Gui, X. An and W. Chang, Crystal structure of spinach major lightharvesting complex at $2.72 \AA$ resolution, Nature, 428 , 287-292 (2004).

55. B. Loll, J. Kern, W. Saenger, A. Zouni and J. Biesiadka, Towards complete cofactor arrangement in the $3.0 \AA$ resolution structure of photosystem II, Nature, 438, 1040-1043 (2005).

56. A. A. Pascal, Z. Liu, K. Broess, van Oort, B. H. van Amerongen, C. Wang, P. Horton, B. Robert, W. Chang and A. Ruban, Molecular basis of photoreception and control of photosynthetic light-harvesting, Nature, 436, 134-137 (2005)

57. A. Zouni, H.-T. Witt, J. Kern, P. Fromme, N. Krauß, W. Saenger and P. Orth, Crystal structure of photosystem II from Synechococcus elongatus at $3.8 \AA$ resolution, Nature, 409, 739-743 (2001).

58. P. Heathcote, P. K. Fyfe and M. R. Jones, Reaction centres: the structure and evolution of biological solar power, Trends Biochem. Sci., 27, 79-87 (2002).

59. K. N. Ferreira, T. M. Iverson, K. Maghlaoui, J. Barber and S. Iwata, Architecture of the photosynthetic oxygen-evolving center, Science, 303, 1831-1838 (2004).

60. N. Kamiya and J.-R. Shen, Crystal structure of oxygenevolving photosystem II from Thermosynechococcus vulcanus at 3.7 A resolution, Proc. Nat. Acad. Sci., 100, 98-103 (2003).

61. N. Krauß, Mechanisms for photosystems I and II, Curr. Op. Chem. Biol., 7, 540-550 (2003).

62. C. W. Hoganson, A metalloradical mechanism for the generation of oxygen from water photosynthesis, Science, 277, 1953-1956 (1997).

63. G. Kurisu, H. Zhang, J. L. Smith and W. A. Cramer, Structure of the cytochrome $b_{6} f$ complex of oxygenic photosynthesis: tuning the cavity, Science, 302, 1009-1014 (2003).

64. P. Jordan, P. Fromme, H.-T. Witt, O. Klukas, W. Saenger and N. Krauß, Three-dimensional structure of cyanobacterial photosystem I at $2.5 \AA$ resolution, Nature, 411, 909-917 (2001). 
65. W. Kühlbrandt, Chlorophylls galore, Nature, 411, 896-897 (2001).

66. C. M. Bruns and P. A. Karplus, Refined crystal structure of spinach ferredoxin reductase at $1.7 \AA$ resolution: oxidized, reduced and 2 '-phospho-S'-AMP bound states, J. Mol. Biol., 247, 124-145 (1995).

67. A. Ben-Shem, F. Frolow and N. Nelson, Crystal structure of plant photsystem I, Nature, 426, 630-635 (2003).

68. J. Deisenhofer and H. Michel, The photosynthetic reaction center from purple bacterium Rhodopseudomonas viridis, Science, 245, 1463-1473 (1989).

69. G. C. Wagner, R. J. Kassner and M. D. Kamen, Redox potentials of certain vitamins $\mathrm{K}$ : implications for a role in sulfite reduction by obligately anaerobic bacteria, Proc. Nat. Acad. Sci., 71, 253-256 (1974).

70. C. Smith and E. J. Wood, Energy in Biological Systems, Chapman and Hall, London, 1991.

71. C. Walsh, Flavin coenzymes: at the crossroads of biological redox chemistry, Acc. Chem. Res., 13, 148-155 (1980).

72. H. Beinert, R. H. Holm and E. Münck, Iron-sulfur clusters: nature's modular, multipurpose structures, Science, 277, 652-659 (1997).

73. J. J. R. Fraústo da Silva and R. J. P. Williams, The Biological Chemistry of the Elements, Oxford University Press, Oxford, 1993.

74. R. E. Sharp and S. K. Chapman, Mechanisms for regulating electron transfer in multi-centre redox proteins, Biochim. Biophys. Acta, 1432, 143-158 (1999).

75. G. Guidotti, Membrane proteins, Ann. Rev. Biochem., 41, 731-752 (1972).

76. H. A. Schwertner and J. B. Biale, Lipid composition of plant mitochondria and of chloroplasts, J. Lipid Res., 14, 235-242 (1973).

77. J. E. Vance and R. Steenbergen, Metabolism and functions of phosphatidylserine, Prog. Lipid Res., 44, 207-234 (2005).

78. A. D. Postle, Composition and role of phospholipids in the body, in Encyclopedia of Human Nutrition, B. Caballero, L. Allen and A. Prentice (eds.), Elsevier Science, London, 2005, pp 132-142.

79. A. G. Mauk and G. R. Moore, Control of metalloprotein redox potentials: what does site-directed mutagenesis of hemoproteins tell us? J. Bio. Inorg. Chem., 2, 119-125 (1997).

80. G. Battistuzzi, M. Borsari and M. Sola, Medium and temperature effects on the redox chemistry of cytochrome c, Eur. J. Inorg. Chem., 12, 2989-3004 (2001).

81. R. Varadarajan, T. E. Zewert, H. B. Gray and S. G. Boxer, Effects of buried ionizable amino acids on the reduction potential of recombinant myoglobin, Science, 243, 69-72 (1989).

82. S. L. Springs, S. E. Bass, G. Bowman, I. Nodelman, C. E. Schutt and G. L. McLendon, A multigeneration analysis of cytochrome $b_{562}$ redox variants: evolutionary strategies for modulating redox potential revealed using a library approach, Biochem., 41, 4321-4328 (2002).
83. R. P. Swenson and G. D. Krey, Site-directed mutagenesis of tyrosine-98 in the flavodoxin from Desulfovibrio vulgaris (Hildenborough): regulation of oxidation-reduction properties of the bound FMN cofactor by aromatic, solvent, and electrostatic interactions, Biochem., 33, 8505-8514 (1994).

84. Z. Zhou and R. P. Swenson, Electrostatic effects of surface acidic amino acid residues on the oxidation-reduction potentials of the flavodoxin from Desulfovibrio vulgaris (Hildenborough), Biochem., 34, 3183-3192 (1995).

85. Z. Zhou and R. P. Swenson, The cumulative electrostatic effect of aromatic stacking interactions and the negative electrostatic environment if the flavin mononucleotide binding site is a major determinant of the reduction potential of the flavodoxin from Desulfovibrio vulgans (Hildenborough), Biochem., 35, 15980-15988 (1996).

86. E. C. Breinlinger, C. J. Keenan and V. M. Rotello, Modulation of flavin recognition and redox properties through donor atom- $\pi$ interactions, J. Am. Chem. Soc., 120, 8606-8609 (1998).

87. E. C. Breinlinger and V. M. Rotello, Model systems for flavoprotein activity. Modulation of flavin redox potentials through $\pi$-stacking interactions, J. Am. Chem. Soc., 119, 1165-1166 (1997).

88. H. B. Gray, B. G. Malmström and R. J. P. Williams, Copper coordination in blue proteins, J. Biol. Inorg. Chem., 5, 551-559 (2000).

89. A. M. Kuznetsov and J. Ulstrup, Electron Transfer in Chemistry and Biology. An Introduction to the Theory, John Wiley \& Sons Ltd., Chichester 1999.

90. R. A. Marcus, Electron transfer reactions in chemistry: theory and experiment, Angew. Chem. Int. Ed. Engl., 32, 1111-1121 (1993).

91. R. A. Marcus and N. Sutin, Electron transfers in chemistry and biology, Biochim. Biophys. Acta, 811, 265-322 (1985).

92. J. R. Winkler and H. B. Gray, Electron transfer in rutheniummodified proteins, Chem. Rev., 92, 369-379 (1992).

93. C. C. Moser, J. M. Keske, K. Warncke, R. S. Farid and P. L. Dutton, Nature of biological electron transfer, Nature, $\mathbf{3 5 5}$, 796-802 (1992).

94. H. B. Gray and J. R. Winkler, Electron tunneling through proteins, Quart. Rev. Biophys., 36, 341-372 (2003).

95. J. R. Heath and M. A. Ratner, Molecular electronics, Phys. Today, 43-49 (2003).

96. A. Nitzan and M. A. Ratner, Electron transport in molecular wire junctions, Science, 300, 1384-1389 (2003).

97. S. S. Isied, M. Y. Ogawa and J. F. Wishart, Peptide-mediated intramolecular electron transfer: long-range distance dependence, Chem. Rev., 92, 381-394 (1992).

98. D. N. Beratan, J. N. Betts and J. N. Onuchic, Protein electron transfer rates set by the bridging secondary and tertiary structure, Science, 252, 1285-1288 (1991).

99. D. N. Beratan, J. N. Onuchic, J. N. Betts, B. E. Bowler and H. B. Gray, Electron-tunneling pathways in ruthenated proteins, J. Am. Chem. Soc., 112, 7915-7921 (1990). 
100. D. N. Beratan, J. N. Onuchic, J. R. Winkler and H. B. Gray, Electron-tunneling pathways in proteins, Science, 258, 1740-1741 (1992).

101. H. B. Gray and J. R. Winkler, Long-range electron transfer, Proc. Nat. Acad. Sci., 102, 3534-3539 (2005).

102. R. Langen, I.-J. Chang, J. P. Germanas, J. H. Richards, J. R. Winkler and H. B. Gray, Electron tunneling in proteins: coupling through a $\beta$ strand, Science, 268, 1733-1735 (1995).

103. C. C. Page, C. C. Moser, X. Chen and P. L. Dutton, Natural engineering principles of electron tunnelling in biological oxidation-reduction, Nature, 402, 47-52 (1999).

104. C. C. Page, C. C. Moser and P. L. Dutton, Mechanism for electron transfer within and between proteins, Curr. Op. Chem. Biol., 7, 551-556 (2003).

105. J. N. Onuchic, D. N. Beratan, J. R. Winkler and H. B. Gray, Pathway analysis of protein electron-transfer reactions, Ann. Rev. Biophys. Biomol. Struct., 21, 349-377 (1992).

106. H. B. Gray and J. R. Winkler, Electron transfer in proteins, Ann. Rev. Biochem., 65, 537-561 (1996).

107. J. Lin, I. A. Balabin and D. N. Beratan, The nature of aqueous tunneling pathways between electron-transfer proteins, Science, 310, 1311-1313 (2005).

108. D. S. Goodsell and A. L. Olson, Soluble proteins: size, shape and function, Trends Biochem. Sci., 18, 65-68 (1993).

109. P. A. Srere, Why are enzymes so big? Trends Biochem. Sci., 9, 387-390 (1984).

110. T. A. Payens, Why are enzymes so large? Trends Biochem. Sci., 8, 46 (1983).

111. P. A. Karplus and C. M. Bruns, Structure-function relations for ferredoxin reductase, J. Bioenerg. Biomembr., 26, 89-99 (1994).

112. P. A. Karplus, M. J. Daniels and J. R. Herriott, Atomic structure of ferredoxin-NADP + reductase: prototype for a structurally novel flavoenzyme family, Science, 251, 60-66 (1991).

113. P. A. Karplus and G. E. Schulz, Substrate binding and catalysis by glutathione reductase as derived from refined enzyme: substrate crystal structures at $2 \AA$ resolution, $J$. Mol. Biol., 210, 163-180 (1989).

114. E. F. Pai, P. A. Karplus and G. E. Schulz, Crtystallographic analysis of the binding of NADPH, NADPH fragments, and NADPH analogues to glutathione reductase, Biochem., 27, 4465-4474 (1988).

115. H. C. Berg, Keeping up with the $\mathrm{F}_{1}$-ATPase, Nature, 394, 324-325 (1998).

116. P. D. Boyer, The ATP synthase - a splendid molecular machine, Ann. Rev. Biochem., 66, 717-749 (1997).
117. P. D. Boyer, What makes ATP synthase spin? Nature, 402, 247-249 (1999).

118. A. E. Senior and J. Weber, Happy motoring with ATP synthase, Nature Struct. Mol. Biol., 11, 110-112 (2004).

119. T. M. Duncan, V. V. Bulygin, Y. Zhou, M. L. Hutcheon and R. L. Cross, Rotation of subunits during catalysis by Escherichia coli $\mathrm{F}_{1}$-ATPase, Proc. Natl. Acad. Sci., 92, 10964-10968 (1995).

120. Y. Zhou, T. M. Duncan and R. L. Cross, Subunit rotation in Escherichia coli $\mathrm{F}_{0} \mathrm{~F}_{1}$-ATPase synthase during oxidative phosphorylation, Proc. Natl. Acad. Sci., 94, 10583-10587 (1997).

121. D. Sabbert, S. Engelbrecht and W. Junge, Intersubunit rotation in active F-ATPase, Nature, 381, 623-625 (1996).

122. V. K. Rastogi and M. E. Girvin, Structural changes linked to proton translocation by subunit $c$ of the ATP synthase, Nature, 402, 263-268 (1999).

123. S. P. Tsunoda, R. Aggeler, M. Yoshida and R. A. Capaldi, Rotation of the $c$ subunit oligomer in fully functional $\mathrm{F}_{1} \mathrm{~F}_{0}$ ATP synthase, Proc. Natl. Acad. Sci., 98, 898-902 (2001).

124. H. Noji, R. Yasuda, M. Yoshida and K. J. Kinosita, Direct observation of the rotation of $\mathrm{F}_{1}$-ATPase, Nature, 386, 299-302 (1997).

125. R. Yasuda, H. Noji, K. J. Kinosita and M. Yoshida, $F_{1^{-}}$ ATPase is a highly efficient molecular motor that rotates with discrete $120^{\circ}$ steps, Cell, 93, 1117-1124 (1998).

126. R. Yasuda, H. Noji, M. Yoshida, K. Kinoshita and H. Itoh, Resolution of distinct rotational sunsteps by submillisecond kinetic analysis of $\mathrm{F}_{1}$-ATPase, Nature, 410, 898-904 (2001).

127. M. Diez, B. Zimmermann, M. Börsch, M. König, E. Schweinberger, S. Steigmiller, R. Reuter, S. Felekyan, V. Kudryavtsev, C. A. M. Seidel and P. Gräber, Proton-powered subunit rotation in single membrane-bound $\mathrm{F}_{0} \mathrm{~F}_{1}$-ATP synthase, Nature Struct. Mol. Biol., 11, 135-141 (2004).

128. H. Itoh, A. Takahashi, K. Adaxhi, H. Noji, R. Yashuda, M. Yoshida and K. Kinoshita, Mechanically driven ATP synthesis by $\mathrm{F}_{1}$-ATPase, 427, 465-468 (2004).

129. J. P. Abrahams, A. G. W. Leslie, R. Lutter and J. E. Walker, Structure at $2.8 \AA$ resolution of $\mathrm{F}_{1}$-ATPase from bovine heart mitochondria, Nature, 370, 621-628 (1994).

130. W. Junge and N. Nelson, Nature's rotary electromotors, Science, 308, 642-644 (2005).

131. T. Meier, P. Polzer, K. Diederichs, W. Welte and P. Dimroth, Structure of the rotor ring of F-type $\mathrm{Na}^{+}$-ATPase from Ilyobacter tartaricus, Science, 308, 659-662 (2005).

132. T. Murata, I. Yanato, Y. Kakinuma, A. G. W. Leslie and J. E. Walker, Structure of the rotor of the V-type $\mathrm{Na}^{+}$-ATPase from Enterococcus hirae, Science, 308, 564-659 (2005). 
